Working Paper in Economics No. 741

\title{
Transition to Agriculture and First State Presence: A Global Analysis
}

Oana Borcan, Ola Olsson, Louis Putterman

Department of Economics, September 2018 


\title{
Transition to Agriculture and First State Presence: A Global Analysis
}

\author{
Oana Borcan ${ }^{\mathrm{a}}$, Ola Olsson ${ }^{\mathrm{b}}$, Louis Putterman ${ }^{1 \mathrm{c}}$ \\ ${ }^{a}$ School of Economics, University of East Anglia, Norwich NR4 7TJ, United Kingdom \\ ${ }^{b}$ Department of Economics, University of Gothenburg, Gothenburg 40530, Sweden \\ ${ }^{c}$ Department of Economics, Brown University, Providence RI 02912, USA
}

\begin{abstract}
It has often been observed that the emergence of states in a region is typically preceded by an earlier transition to agricultural production. Using new data on the date of first state emergence within contemporary countries, we present a global scale analysis of the chronological relationship between the transition to agriculture and the subsequent emergence of states. We find statistically significant relationships between early reliance on agriculture and state age in all sub-samples. Our findings show that this relationship is not markedly different in cases where states were imposed from outside or when they emerged through internal origination.
\end{abstract}

Keywords: Agricultural Transition, States

JEL classification: $N 50,043$

A common observation of anthropology and archaeology is that emergence of the macro polities we call states followed by a few millennia the transitioning of populations from reliance on foraging to reliance on crop cultivation and animal husbandry as their main source of calories (Service and Sahlins, 1960; Service, 1971; Diamond, 1997; Johnson and Earle, 2000). Typically, the pattern has been remarked on with reference to a small number of cases, limiting tests for statistical regularity. We partially address this omission by using recently compiled data that permit the contours of the

\footnotetext{
${ }^{1}$ Corresponding author. E-mail: louis_putterman@brown.edu

Louis Putterman wishes to thank Jared Diamond and Alan Farahani for aiding his understanding of the literatures on early agricultures and states in the course of ongoing research.
} 
agriculture-to-state passage to be studied statistically on a global scale. Our data take as observational units the territories of 159 countries of the year $2000 \mathrm{CE}$, accounting for 96 percent of all countries having populations above 0.5 million in that year. The countries included account for over 90 percent of the worlds population and for almost 99 percent of its land surface, excluding Antarctica. We code for presence or absence of states beginning $3500 \mathrm{BCE}$, the estimated date of transition to centralized political organization above tribal level in southern Mesopotamia.

All countries covered have achieved their first state presence by $2000 \mathrm{CE}$, with considerable variation in timing and nature of state emergence. We identify as "pristine" those states which emerged in the absence of nearby models of macro polity. Such states arose in eight countries of today (hereafter countries). We designate as "externally originated" the states of 72 countries where initial state emergence is attributed to annexation or colonization from outside. We identify as "internally originated" states 79 intermediate cases in which states emerged earliest as the result of internal political developments but in a world region in which large scale polities were gradually appearing in evident diffusion from an originally pristine core.

We find a statistically significant association between time of transition to agriculture and time of state emergence even when controlling for geographic and climatic factors, distance from the relevant diffusion zone's pristine state, and time of first human settlement, as well as when addressing potential endogeneity problems by using an instrumental variables strategy. Our estimated average time from primary reliance on agriculture to full state emergence is 3406 years for pristine, 3100 years for internally originated and 2731 years for externally originated states, and our estimates imply that a one millennium earlier transition to agriculture among non-pristine states predicts a 315-410 year earlier state emergence depending on the exact specification.

Our paper is related to a few existing works on the transition to agriculture and state origins. Petersen and Skaaning (2010) and Boix (2015) estimate correlations between agricultural transition and state emergence, with the former adding supplemental estimates to a previous compilation of state age data by Putterman (2007) that extended to $1 \mathrm{CE}$, and the latter using dates said to be based on books published in the 1970s through 1990s, ${ }^{2}$

\footnotetext{
${ }^{2}$ The year of first state presence is not shown in the book, nor is any public repository of the data or country by country detailing of sources indicated.
} 
versus our reliance on data developed by us in BOP 2014 and BOP 2018, and detailed in the latter's Appendix. Differences in data and methodology include our use of multiple controls including diffusion zone mapping and revised human arrival time, our distinction between pristine, internally originated and externally originated states, and our attention to both protostate and full state transitions. See the "Details on Methods" section of the Appendix for further discussion.

The paper proceeds as follows: In section 1, we present the empirical strategy and the data. In section 2 , we show the main results, which are then further discussed in a concluding section 3.

\section{Empirical Specification and Data}

Our main empirical specification is

$$
\text { StateAge } e_{i j}=\alpha+\beta \text { TimeAgri } i_{i j}+\gamma D_{j}+\delta X+\epsilon_{t}
$$

where the dependent variable State Age $e_{t}$ is the time in millennia (ky) in 2000 $\mathrm{CE}$ since the emergence of the first state in a territory defined by the borders of current country $i$ in diffusion region $j$, TimeAgri $i_{i j}$ is the time elapsed since the transition to agriculture in $i(\mathrm{ky}), D_{j}$ is a dummy for agricultural diffusion region $j$, and $X_{i j}$ is a set of control variables defined below.

Country level units defined over year 2000 borders are used because our research on state age has focused on how early history influences differences in economic and institutional outcomes today, and because comparable estimates have not been assembled for the world as a whole at grid cell or other finer levels. State Age is extracted from the State History Index developed originally by Bockstette, Chanda, and Putterman (2002) and extended by Borcan, Olsson, and Putterman (2018) to account for states emerged before the Common Era, in 159 modern-day country territories.

Data are compiled guided by the conceptions of Service (1960), Tilly (1990), Johnson and Earle (2000), and adopting the convention that political structures from bands to simple chiefdoms fall short of being states, whereas paramount chiefdoms which incorporate multiple individually substantial chiefdoms can be understood as incipient (or proto-) states. A still larger scale including a specialized administration and soldiery is required to qualify as a full state. Borcan, Olsson, and Putterman (2018) find the first presence of a state to have occurred in the form of a paramount chiefdom in 
present-day Iraq in $3500-3401$ BCE, with full state designation beginning there in $3400 \mathrm{BCE}$.

We employ two dimensions of the state history index compiled by BOP (2018) in our analysis. First, BOP identify the first year in which a country was home to a paramount chiefdom or full state. We use time from 2000 CE to first appearance of either of the latter as our main measure of state age, with time to first full state alone as an alternative measure in analyses of robustness. Second, BOP determine whether a country's first state was created by external colonizers vs. by internal actors, permitting us to distinguish between internally originated and externally originated states, as mentioned above. To these, we add our identification of pristine states and our assignments of each non-pristine state to the diffusion zone of one or another pristine state, as detailed in Appendix Tab. A1.

Time of transition to agriculture is defined conceptually as approximate year in which a substantial population in some part of a country relied mainly on cultivated crops and domesticated animals for their subsistence, relying on expert compilations including Smith (1995), MacNeish (1992), and Piperno and Pearsall (1998). We note that first domestication of individual crops and animals occurred at considerably earlier dates than we assign for emergence of agriculturally-based society (e.g., South America (Piperno, 2011)), but these domesticates were at first contributing to diets still dominated by foraged plants and animals.

To control for potential influence on timing of the gradual spread of state polities across regions, a process driven not only by conquest and attempts to stave off conquest but possibly also by example, we assign each nonpristine country to a diffusion zone. For example, the first Mesopotamian states inspired instances of state emergence around the Mediterranean and ultimately northward to Scandinavia, Britain and Ireland and southward to Mali; the first (or at least subsequent) Indian states likely influenced the emergence of states in Cambodia, Indonesia, and neighbors; the first Chinese states ones in Korea and Japan. Distance of each country to the pristine state with which it is identified is given in thousands of $\mathrm{km}$ of geodesic distance, from initiation points at Uruk (Iraq), Erlitou (China), Mohenjo Daro (Indus Valley), Chavin de Huantar (Chavin, Peru), Monte Alban (Oaxaca Valley, Mexico), and Hierakonpolis (Egypt). ${ }^{3}$

\footnotetext{
${ }^{3}$ For a discussion of state emergence at these initiation points, see Spencer (2010).
} 
Designation of pristine states is based on the assumption that the Mesoamerican and Andean civilizations each arose with no direct influence of ideation regarding political structures either from the other or from Mesopotamia. These three fully independent points of state origin are linked by us to the countries most often associated with their initial centers of gravity, i.e. Mexico, Peru and Iraq (our findings would change little were we to substitute, say, Guatemala for Mexico or Bolivia for Peru). Although some Fertile Crescent crops had reached China by the time of state emergence there, proto-state building in that East Asian civilizational core almost certainly arose mainly from local crop and animal packages, with no evidence that knowledge of states to China's west influenced emergence of Erlitou. The Indus Valley cities in what are presently India and Pakistan are also treated as giving rise to states independently of Mesopotamia, despite considerably stronger influence of West Asian agriculture, since signs of direct cultural influence from Mesopotamia are limited. We treat the first state within present-day Iran, on the Susiana Plain, as pristine although not as an independent origin point for state diffusion, because despite influence from contacts with pre-state Uruk, it and southern Mesopotamia gave rise to states at nearly the same time. Egyptian civilization, while also based on the West Asian agricultural package, is viewed as generating macro political structures independently of and only slightly after Mesopotamia, despite considerably later transition to agriculture (Allen, 1997).

We also include a number of controls $X$ in our estimations to take into account anthropological and geographic characteristics of the territories in our sample, which may influence state emergence. The first is the time (in ky) since the initial uninterrupted settlement by anatomically modern humans (in $2000 \mathrm{CE}$ ), which was originally coded by Ahlerup and Olsson (2012) and updated in 2018 following recent developments in Oppenheimer (2012a, 2012b, 2014). We control for time of first human settlement because both agriculture and states could conceivably have emerged many thousands of years earlier in Africa and the Near East than in (for example) Ireland, Australia, or the Americas, by virtue of later arrival of humans to the latter land masses. We follow the assumption of Oppenheimer and collaborators according to which anatomically modern humans (AMH) made a single decisive exit from Africa to Eurasia by initially following a southern Asian coastal route, an approach that treats earlier signs of AMH in Fertile Crescent and other sites as largely lacking in longer-term contribution to the AMH gene pool, although the dates we assign to Fertile Crescent countries - 52 kya- 
are earlier than in Oppenheimer (2003, 2012a, 2012b, 2014) and Soares et al. (2009) in recognition of the earlier dates preferred by other experts. See the "Details on Methods" section of the Appendix for further information, including the assumption that earlier AMH appearance in the Fertile Crescent was probably not the decisive long-term exit from Africa. We judge it impossible at present to assign firm dates for individual sub-Saharan African countries, and accordingly use the 135 kya estimate of Oppenheimer (2003) for the entire region, while also confirming the robustness of our qualitative results to adopting a more recent estimate, $90 \mathrm{kya}$ (see discussion below). We also try substituting as an alternate proxy for AMH arrival time the (mainly) land distance from Addis Ababa, used in several studies of long history by economists, on assumption that AMH radiation throughout the world begins somewhere in or near present-day Ethiopia.

The geographic controls in $X$ include absolute latitude, an indicator of whether the present-day country is landlocked, distance to coast and rivers, mean elevation, temperature, precipitation, and percentage population at risk of contracting malaria. We also calculate and control for distances (i.e. the length of the shortest curve) to the relevant pristine state - the nucleus of the diffusion region. All the variables' construction is detailed in the Appendix.

Although we control for an extensive set of anthropological and geographical variables, we recognize that there might potentially still be omitted factors that influence both the transition to agriculture and the emergence of states. To address this issue, we also use an instrumental variables (IV) approach. The IVs are used in a two-step estimation procedure (two-stage least squares), where in the first stage the instruments are used to predict the time since transition to agriculture, and in the second stage, the resulting values are themselves used as predictors of time since state emergence.

As instruments we choose the biogeographic endowments that are well established determinants of the transition to agriculture: the number of domesticable plants and animals available in 10,000 BCE in different regions across the globe, compiled by Hibbs and Olsson (2004). We also use the index from Olsson and Hibbs (2005) summarizing the geographical characteristics critical for the emergence and diffusion of agriculture: climate, latitude and East-West continental axis and continent size (geography). These variables plausibly satisfy the conditions required for good instruments: they are relevant in explaining the timing of the switch to agriculture (confirmed by high F-statistics in the first stage) and their only plausible contribution to state 
emergence was to facilitate the food surplus which led to large-scale organization and the emergence of professional classes outside the agricultural sector.

The biogeography variable has been used as an instrument for the timing since the transition to agriculture by Ashraf and Galor (2011), Ang (2015), and Ertan, Fiszbein, and Putterman (2016) to explain historical and contemporary economic performance. Moreover, Bleaney and Dimico (2011) show that domesticable plants and animals do not directly impact income in 2000 $\mathrm{CE}$, indicating the exclusion restriction for these to be valid instruments is satisfied.

We proceed to show correlations and ordinary least square estimates of the relationship between state age and the time since the transition to agriculture in pristine states. We then present regression results for non-pristine states from a two-step procedure utilizing instrumental variables aimed at delivering the causal link between agriculture and timing of state emergence.

\section{Results}

\subsection{Agricultural Transition and State Emergence in Pristine States}

The six clusters of pristine states widely accepted by anthropologists emerged on the territories of present-day Iran/Iraq, Egypt, India/Pakistan, China, Mexico and Peru. The time before 2000 CE since the transition to agriculture in these eight countries is strongly predictive of the timing of autochthonous and independent state emergence (Fig 1A), with a correlation coefficient of 0.85. A fitted line emerges very close to the cases of Mexico and Peru, India and Pakistan, Iran and Iraq, indicating that state formation would have occurred around 400 years earlier for each millennium earlier that reliance on agriculture emerged. In Egypt, the lag between the transitions to agriculture and the presence of state is shorter than predicted by the slope, and vice versa in China. Note that these estimates are based on our definition of state age including the early phase of proto-states. Political institutions come considerably later in India and Pakistan than in China if we go by full state rather than proto-state. Whether the relationship in the figure represents a causal link due to the demand for large-scale socio-political organization which agriculture would have created, is less controversial in

pristine states, where the transition to agriculture took place on average 3.4 ky before state formation. 
Figure 1: State age and time since transition to agriculture in pristine (A) and non-pristine states (B).

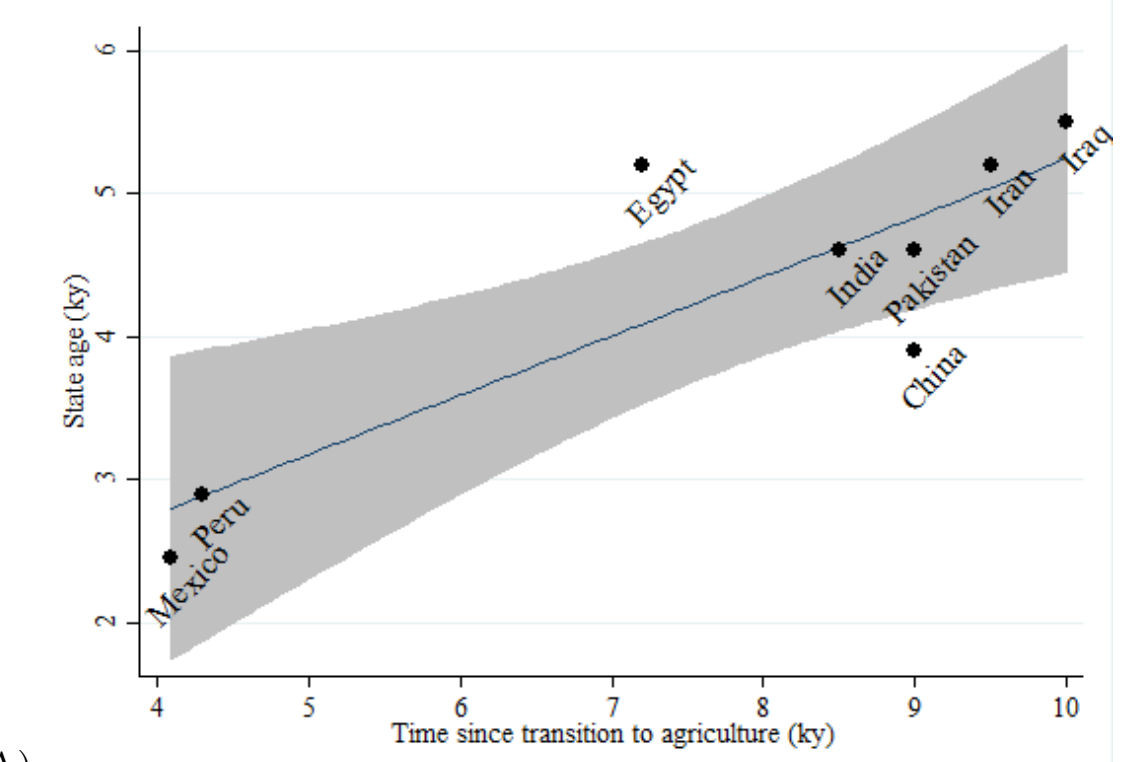

(A)

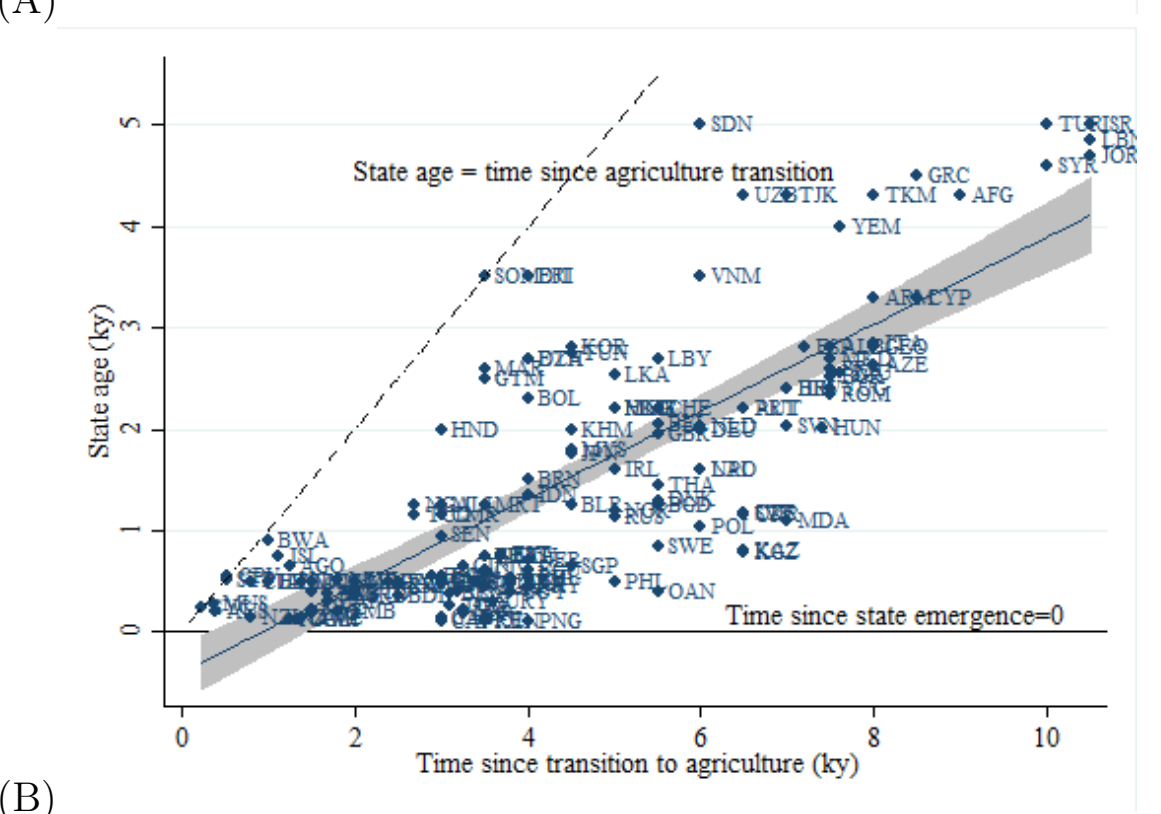

State age is plotted against the time since the transition to agriculture in millennia (ky) before $2000 \mathrm{CE}$ in both figures. (B) includes three-letter isocodes for individual countries and a thin dashed line to the left showing where time since agricultural transition equals state age. Both figures include a fitted OLS regression line with a 95 percent confidence interval for the predicted mean (grey area). State age is calculated in Borcan, Olsson, and Putterman (2018). The time since agricultugal transition is compiled by Putterman and Trainor (2006 [revised 2018]). 
Nevertheless, there remains the possibility that anthropological factors, such as when humans first settled on these territories, or physical factors, such as geographic and climatic conditions, may have favored both the early switch to domesticated crops and animals and the early state formation in these regions. To account for these factors, we run ordinary least squares regressions with the time since state emergence as the dependent variable and time since the agricultural transition alongside such factors, as independent variables (Tab. 1), focusing first on the pristine state sample. Including these controls increases the influence of agriculture to over 570 years of earlier transition to state institutions for each millennium of early agriculture. Overall, the estimates suggest the emergence of populations depending on agriculture was a key determinant of the emergence of pristine states.

Table 1: State age and the time since transition to agriculture in pristine states.

\begin{tabular}{lcccc}
\hline \hline & \multicolumn{5}{c}{ State Age (ky) } \\
\hline & $(1)$ & $(2)$ & $(3)$ & $(4)$ \\
Time since agriculture (ky) & $0.414^{* * *}$ & $0.573^{* *}$ & $0.591^{* *}$ & $0.587^{* *}$ \\
& $(0.061)$ & $(0.198)$ & $(0.177)$ & $(0.060)$ \\
Time since first human settlement (ky) & & -0.005 & & \\
& & $(0.014)$ & & \\
Observations & 8 & 8 & 8 & 8 \\
R-squared & 0.729 & 0.760 & 0.925 & 0.979 \\
Controls & No & Yes & Yes & Yes \\
\hline
\end{tabular}

OLS (Ordinary Least Squares) regression estimates of the relationship between state age as of $2000 \mathrm{CE}$ and time since the agricultural transition in eight countries where pristine states emerged. We include the following controls: column 2 - country centroid absolute latitude and time since first human settlement; column 3: distance to coast and rivers and average elevation; column 4 - precipitation, average temperature, and percentage people at risk of malaria. Time since initial uninterrupted settlement by modern humans (before $2000 \mathrm{CE}$ ) was originally coded by Ahlerup and Olsson (2012) and updated in 2018 following Oppenheimer (2012a, 2012b, 2014). Heteroskedasticity robust standard errors in parentheses. ${ }^{* * *} \mathrm{p}<0.01,{ }^{* *} \mathrm{p}<0.05,{ }^{*} \mathrm{p}<0.1$ 


\subsection{State age and time since agricultural transition in non-pristine states}

From the agricultural cores, the practice of domesticating plants and animals has gradually spread to the periphery of five main regions of agriculture diffusion: West Asia - Europe - North Africa (starting from the Fertile Crescent), Southeast Asia and Oceania (spreading from China), Sub-Saharan Africa (through the Bantu expansion out of the territory of modern-day Cameroon), North and Central America (from Mexico), and South America (starting from the Andes). Soon after the emergence of pristine states, adjacent territories saw the formation of state institutions and large-scale political organization sprung up fast across areas of diffusion which largely (but not entirely) overlap with the agriculture diffusion regions. Some of these states emerged autochthonously (internally-originated states), but were unquestionably influenced by pristine state development in those regions. A prominent example is the spread of mandala states from India into Southeast Asia. Other states emerged as a result of expansion and conquest by pre-existing states (externally-originated states). The Western state diffusion zone, which started in Iraq (the Fertile Crescent), eventually includes many countries of today that were not home to states in our sense (for instance Malawi, Cuba, and New Guinea) before being swept up in the European colonial era. Internally-originated states emerged on average one millennium earlier than externally-originated states, which currently count on average a thousand years of existence.

The positive, bivariate relationship between state age and time since agriculture in 151 non-pristine states is shown in Fig 1B. The best fit line intersects the vertical axis below 0 , consistent with presence of a lag between adoption of agriculture and emergence of a state. With a slope less than unity, this lag tends to be larger in places where the transition to farming occurred earlier. In for instance Turkey (TUR, upper right corner of Fig 1B), states emerged 5 ky after agriculture, whereas the lag was only $0.6 \mathrm{ky}$ in Angola (ANG, lower left corner). In all non-pristine states, the transition to agriculture either preceded or (in a few cases like Seychelles and Somalia) coincided with state formation (mean lag is $2.9 \mathrm{ky}$ ), indicating that the prospect of reverse causality is of little relevance. However, even more so than with pristine states, factors common to both the spread of practices of plant and animal domestication and large-scale political centralization along diffusion regions may cast doubts on whether OLS estimates deliver a mere correlation, or the true impact of early transition to agriculture on state formation. 
To obtain an estimate for which a causal interpretation can be more convincingly argued, we adopt an instrumental variable approach (IV). We identify variables correlated with the time since the adoption of agriculture but uncorrelated with the timing of state emergence, except through their effect on agriculture. Thus, the only link between these instrumental variables and state emergence is one strictly mediated by the emergence of agriculture. These instrumental variables isolate the variation in timing of agriculture adoption that is not confounded by factors also generating variation in timing of state emergence.

Table 2: State age and time since the transition to agriculture in non-pristine states - IV estimates

\begin{tabular}{lccc}
\hline \hline & \multicolumn{3}{c}{ State Age } \\
\hline & $(1)$ & $(2)$ & $(3)$ \\
Time since agriculture (ky) & $0.410^{* * *}$ & $0.315^{* * *}$ & $0.403^{* * *}$ \\
& $(0.034)$ & $(0.048)$ & $(0.078)$ \\
Distance to pristine state & & $-0.106^{* * *}$ & -0.069 \\
& & $(0.028)$ & $(0.058)$ \\
Time since first human settlement (ky) & & -0.000 & -0.002 \\
& & $(0.001)$ & $(0.002)$ \\
& & & \\
Observations & 151 & 150 & 123 \\
R-squared & 0.607 & 0.638 & 0.820 \\
Controls & No & No & Yes \\
Diffusion Region & No & No & Yes \\
First stage F-statistic & 103.44 & 62.37 & 22.51 \\
Wooldridge's test statistic & $1.87 \mid .39$ & $2.96 \mid .23$ & $.96 \mid .62$ \\
\hline
\end{tabular}

Two-stage least squares regression with state age explained by time since transition to agriculture. Instrumental variables: biogeography and geography. Heteroskedasticity-robust standard errors in parentheses. ${ }^{* * *} \mathrm{p}<0.01,{ }^{* *} \mathrm{p}<0.05,{ }^{*} \mathrm{p}<0.1$

Using these instruments, we obtain IV estimates of around 0.315 to 0.410 ky of earlier state emergence for each additional $1 \mathrm{ky}$ of reliance on farming (Tab. 2). We also report these estimates after controlling for the distance of states from their diffusion regions' pristine state (column 2); we also 
control for unobserved characteristics of the state diffusion regions through region indicators and we additionally control for geographic and climatic characteristics (column 3). These further controls ensure that our main estimate captures the influence of agriculture on state formation, and not simply spillovers of institutional developments in neighboring territories along the diffusion paths from pristine states.

In the Appendix we also report regressions where we proxy patterns of initial human settlement by the migration distance from East Africa, which leave the main estimates unchanged (Tab. A11). We run other robustness tests, where we include: only plants and animals as instruments (Tab. A8); a slightly modified geography index where islands are assigned the nearest continent's axis ratio (Tab. A9); an interaction term that captures how state diffusion speed (proxied by distance to pristine state) may vary depending on how early the pristine state made the transition to agriculture (Tab. A10). We find consistently significant and similar estimates of the impact of agriculture timing on state formation.

Two features of these results are noteworthy: first, the IV estimates are only slightly smaller than the corresponding OLS estimates (Tab. A7 in Appendix, estimates around 0.335-0.430); second, the estimates in non-pristine states are very similar to the estimates for pristine states. Overall, the regression results suggest that, regardless of whether state formation ensued independently or through conquest, earlier reliance on agriculture significantly expedited state emergence: states emerged at least 400 years faster for each millennium earlier that reliance on agriculture began.

Finally, we compare the estimates in internally-originated states with those in externally-originated states. We may expect a stronger relationship between agriculture and state emergence in internally-originated states, since the expansion of power from other territories or conquest of new territories may have simultaneously brought agricultural technologies and macro political governance to those territories. On the other hand, territories not yet politically-organized, but where agriculture was the main mode of food production may have been more attractive, thus becoming earlier targets for expanding states. Overall, whether or not agriculture had a different impact in internally and externally originated states remains an empirical question.

The simple association between state age and time since the transition to agriculture appears positive for both types of states, but slightly weaker in the externally-originated states, where the line fitted through the scatter of cases has a flatter slope and a lower R-squared value (Fig. 2). The IV estimates in 
Tab. 3 using biogeography and geography as instruments confirm that there is a slightly weaker link between agriculture and state transition in externallyoriginated states than in those where the initial rule emerged from within the territory. This is a likely consequence of the existence of externally-originated states, such as those in Cape Verde and the Seychelles, where agriculture and state institutions were brought in concomitantly.

Figure 2: State age and time since the transition to agriculture in non-pristine internallyvs externally-originated states.

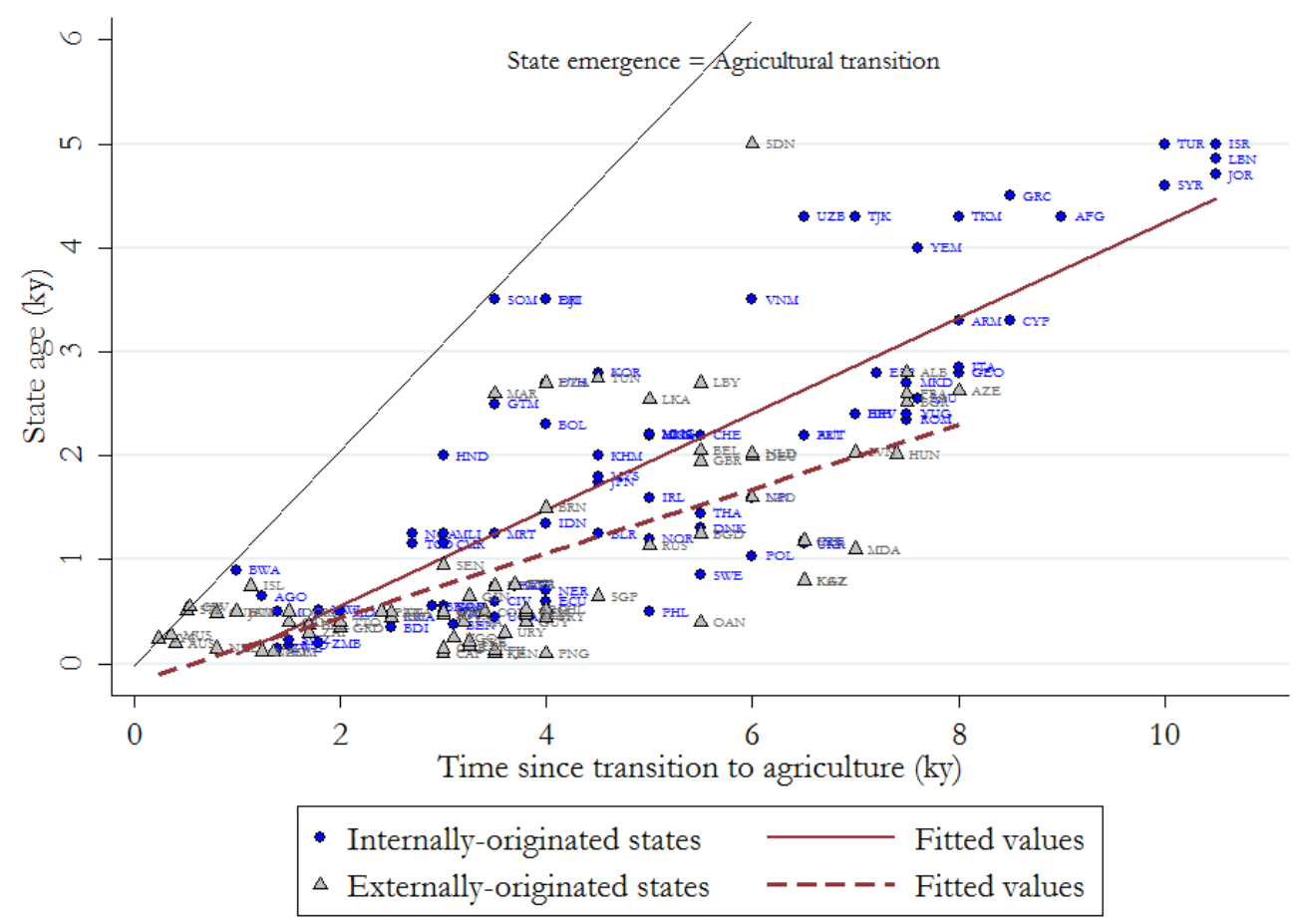

State age is plotted against the time since the transition to agriculture in $2000 \mathrm{CE}$. The figure includes separate fitted OLS regression lines for internally-originated (solid line) and externally-originated states (dashed line). Thin line to the left shows where time since agricultural transition equals time since state emergence. The time since state emergence is calculated in Borcan, Olsson, and Putterman (2018). The timing of the transition to agriculture is compiled by Putterman and Trainor (2006 [revised 2018]). 
Table 3: State age and time since the transition to agriculture in non-pristine states - IV estimates: Internally vs. externally originated states

\begin{tabular}{lcccc}
\hline \hline & \multicolumn{5}{c}{ State Age (ky) } \\
& $(1)$ & $(2)$ & $(3)$ & $(4)$ \\
& & & & \\
& & & \\
Time since agriculture (ky) & $0.396^{* * *}$ & $0.524^{* * *}$ & $0.350^{* * *}$ & $0.304^{* * *}$ \\
& $(0.046)$ & $(0.107)$ & $(0.050)$ & $(0.079)$ \\
Distance to pristine state & & -0.036 & & $-0.078^{*}$ \\
& & $(0.113)$ & & $(0.041)$ \\
Time since first human & & 0.002 & & $-0.006^{* * *}$ \\
settlement (ky) & & $(0.004)$ & & $(0.002)$ \\
& & & & \\
Observations & 79 & 71 & 72 & 52 \\
R-squared & 0.648 & 0.845 & 0.426 & 0.871 \\
Controls & No & Yes & No & Yes \\
Diffusion Region & No & Yes & No & Yes \\
First stage F-statistic & 70.18 & 15.3 & 44.41 & 8.80 \\
Wooldridge's test statistic & $.56 \mid .76$ & $3.47 \mid .18$ & $6.22 \mid .04$ & $8.80 \mid .01$ \\
\hline
\end{tabular}

Two-stage least squares regression estimates of the time since state emergence on time since transition to agriculture, in internally vs. externally originated non-pristine states. Instrumental variables: biogeography and geography. Heteroskedasticity-robust standard errors in parentheses. ${ }^{* * *} \mathrm{p}<0.01,{ }^{* *} \mathrm{p}<0.05,{ }^{*} \mathrm{p}<0.1$

\section{Concluding Remarks}

The association between a population's transition to reliance on domesticated crops and animals for its subsistence, and changes in its political structure culminating in the emergence of states, is strongly evident in our data. To be sure, only the pristine cases might be accepted as fully independent, with the strictest level of independence being limited to four to six cases only. Transition to primary reliance on agriculture is highly correlated with independent state emergence, despite the small sample. Emergence of states through internal political developments in countries that we classify as being in the spread zones of both agriculture and states from the varied core areas including Fertile Crescent and north/central China, must be viewed as 
providing less fully independent evidence.

Nevertheless, the similar way in which time transpires from adoption of agriculture to emergence of states in these cases offers further support for the idea of a process whereby, by facilitating growth of population and density of settlement, need and opportunity for new forms of political organization were likely fostered in similar ways across a large number of localities. Even those cases in which the first macro polity was directly attributable to an external group or empire display a similar pattern at least on average, perhaps because until recent centuries, the conquest and rule of territory was usually focused on areas more populous than those occupied by foragers alone. No countries in our sample display simultaneous arrival of both agriculture and the state from without before that phenomenon became common in the post-1400 colonial era. Our analysis based on the territories of most of the world's countries today thus supports, with expanded coverage and statistical precision, the long held belief that transition to agriculture was in the large majority of cases a prologue to the emergence of states throughout the world.

\section{References}

Ahlerup, Pelle and Ola Olsson. 2012. "The roots of ethnic diversity." Journal of Economic Growth 17 (2): 71-102.

Allen, Robert C. 1997. "Agriculture and the origins of the state in ancient Egypt." Explorations in Economic History 34 (2): 135-54.

Ang, James B. 2015. "What drives the historical formation and persistent development of territorial states?" The Scandinavian Journal of Economics 117 (4): 1134-75.

Ashraf, Quamrul and Oded Galor. 2011. "Dynamics and stagnation in the Malthusian epoch." American Economic Review 101 (5): 2003-41.

Bleaney, Michael and Arcangelo Dimico. 2011 "Biogeographical conditions, the transition to agriculture and long-run growth." European Economic Review 55 (7): 943-54. 
Bockstette, Valerie, Areendam Chanda, and Louis Putterman. 2002. "States and markets: The advantage of an early start." Journal of Economic Growth 7 (4): 347-69.

Boix, Carles. 2015. Political Order and Inequality: Their Foundations and their Consequences for Human Welfare. New York: Cambridge University Press.

Borcan, Oana, Ola Olsson, and Louis Putterman. 2014. "State history and economic development: evidence from six millennia." Brown University Department of Economics Working Paper 2014-6.

Borcan, Oana, Ola Olsson, and Louis Putterman. 2018. "State history and economic development: evidence from six millennia." Journal of Economic Growth 23 (1): 1-40.

Diamond, Jared. 1997. Guns, Germs, and Steel: The Fates of Human Societies. 1st ed. New York: W.W. Norton \& Co.

Ertan, Arhan, Martin Fiszbein, and Louis Putterman. 2016. "Who was colonized and when? A cross-country analysis of determinants." European Economic Review 83: 165-84.

Hibbs, Douglas A. and Ola Olsson. 2004. "Geography, biogeography, and why some countries are rich and others are poor." Proceedings of the National Academy of Sciences 101 (10): 3715-20.

Johnson, Allen W. and Timothy K. Earle. 2000. The Evolution of Human Societies: from Foraging Group to Agrarian State. 2nd ed. Stanford: Stanford University Press.

MacNeish, Richard. 1992. The Origins of Agriculture and Settled Life. Norman: University of Oklahoma Press.

Olsson, Ola and Douglas A. Hibbs. 2005. "Biogeography and long-run economic development." European Economic Review 49 (4): 909-38.

Oppenheimer, Stephen. 2003. Out of Eden: The Peopling of the World. 
London: Constable and Robinson.

Oppenheimer, Stephen. 2012a. "A single southern exit of modern humans from Africa: Before or after Toba?" Quaternary International 258: 88-99.

Oppenheimer, Stephen. 2012b. "Out-of-Africa, the peopling of continents and islands: Tracing uniparental gene trees across the map." Philosophical Transactions of The Royal Society B 367 (1590): 770-84.

Oppenheimer, Stephen. 2014. "Modern humans spread from Aden to the antipodes with passengers and when?" In Southern Asia, Australia and the Search for Human Origins, edited by Robin Dennell and Martin Porr, 228-42. New York: Cambridge University Press.

Petersen, Michael B. and Svend-Erik Skaaning. 2010. "Ultimate causes of state formation: The significance of biogeography, diffusion, and neolithic revolutions." Historical Social Research 35 (3): 200-26.

Piperno, Dolores R. 2011. "The origins of plant cultivation and domestication in the new world tropics: Patterns, process, and new developments." Current Anthropology 52 (S4): S453-70.

Piperno, Dolores R. and Deborah M. Pearsall. 1998. The Origins of Agriculture in the Lowland Neotropics. Cambridge, MA: Academic Press.

Putterman, Louis. 2007. "State antiquity index: Introduction and appendix." Brown University Department of Economics. http://www. brown.edu/Departments/Economics/Faculty/Louis_Putterman/State_Antiquity _ Index_V3\%201\%20update\%20Nov.\%202017.pdf.

Putterman, Louis and Cary A. Trainor. 2006 [Revised 2018]. "Agricultural transition year - country data set." Brown University Department of Economics. http://www.brown.edu/Departments/Economics/ Faculty/Louis_Putterman/agricultural\%20data\%20page.htm.

Service, Elman. 1971. Primitive Social Organization: An Evolutionary Perspective. 2nd ed. New York: Random House. 
Service, Elman and Marshall Sahlins. 1960. Evolution and Culture. Ann Arbor: University of Michigan Press.

Smith, Bruce D. 1995. The Emergence of Agriculture. New York: Scientific American Library.

Soares, Pedro, Luca Ermini, Noel Thomson, Maru Mormina, Teresa Rito, Arne Rhl, Antonio Salas, Stephen Oppenheimer, Vincent Macaulay, and Martin B. Richards. 2009. "Correction for purifying selection: An improved human mitochondrial molecular clock." American Journal of Human Genetics 84 (6): 740-59.

Spencer, Charles S. 2010. "Territorial expansion and primary state formation." Proceedings of the National Academy of Sciences 107 (16): 711926.

Tilly, Charles. 1990. Coercion, Capital, and European States, AD 990-1990. Cambridge, MA: Basil Blackwell. 


\title{
Transition to Agriculture and First State Presence: A Global Analysis SUPPLEMENTARY INFORMATION APPENDIX
}

\author{
Oana Borcan ${ }^{\mathrm{a}}$, Ola Olsson ${ }^{\mathrm{b}}$, Louis Putterman ${ }^{1 \mathrm{c}}$ \\ ${ }^{a}$ School of Economics, University of East Anglia, Norwich NR4 7TJ, United Kingdom \\ ${ }^{b}$ Department of Economics, University of Gothenburg, Gothenburg 40530, Sweden \\ ${ }^{c}$ Department of Economics, Brown University, Providence RI 02912, USA
}

\begin{abstract}
This Supplementary Online Appendix presents further details on methods, in particular on the construction of the main datasets and other data sources, as well as additional figures and tables for a variety of robustness checks.
\end{abstract}

\section{Details on methods}

The state history data used in our paper are identical to those introduced in Borcan, Olsson, and Putterman (2018). Section 4 of that paper describes how the data were created, with additional illustrations in Appendix A of the Supplementary Information. A paragraph or paragraphs explaining the coding for state presence in each country and each half century is available here https://drive.google.com/file/d/1t5p1USIivXK-38urc2d5Fx7X5rHTzxzQ/view.

Details on the sources and decisions on dating transition to agriculture for each country covered in Putterman (2008) can be found in Putterman and Trainor (2006, revised 2018). The revision, undertaken for the present paper, involves the following changes. First, several values in the data file for this source were found to be inconsistent with descriptions in the verbal appendix, and in these cases, the data file was altered to be consistent with the verbal material. The most serious problems identified were first, that the values for number of years before 2000 at which reliance on agriculture began for Germany and Georgia, which should be 6000 and 8000 respectively, had

\footnotetext{
${ }^{1}$ Corresponding author. E-mail: louis_putterman@brown.edu
} 
been mistakenly transposed in the data file; likewise, years before present (present $=2000 \mathrm{CE}$ ) was mistakenly listed as 3,500 instead of the 2,500, for Burundi. Years before present was also wrongly listed as 10,500 instead of 10,000 for Syria, and as 3,500 instead of 3,200 for the United States. Also, although a value of 3,000 is given below for Equatorial Guinea, no value for that country was listed in the data file, so this was added.

In addition to making those changes to the data file, we added data for the first time for the following five island nations: Comoros, Fiji, Iceland, Sao Tome, and Seychelles. Arguments for the dates now assigned have been added in the respective region summaries of the Putterman and Trainor appendix.

The variable called Time since first human settlement is based on the variable called Origtime by Ahlerup and Olsson (2012) which attempts to measure the number of years before year $2000 \mathrm{CE}$ when modern humans first come to live within the territory of each country of year 2000. Dates of human arrival were based on Oppenheimer (2003) with judgments made on assignment of years to countries when required. For the present paper, we attempt to update estimated dates of human arrival while maintaining Oppenheimer's hypothesis that coastal migration through southern Arabia and eastward to coastal Southeast Asia led to the peopling of coastal Asia before that of other parts of the world outside of Africa, the region that was in turn the home to modern humans prior to their exit and dispersion to other continents. Updates follow mainly the ideas in a set of papers and chapters recommended in personal communication by Oppenheimer, in particular Soares et al. (2009) and Oppenheimer (2012a, 2012b, 2014). For further details, see Details on construction of Time since first human settlement.

The variable State diffusion region places countries to one of six regions where state institutions are likely to have spread from a pristine state to adjacent territories. The states widely regarded as pristine are: Mesopotamia (Iraq/Iran, initiation point at Uruk), Erlitou (China, initiation point at the Erlitou site), Indus Valley states (India/Pakistan, initiation point at Mohenjo Daro), Chavin (Peru, initiation point at Chavin de Huantar), Oaxaca Valley states (Mexico, initiation point at Monte Alban), Upper Egypt (Egypt, initiation point at Hierakonpolis). A country's territory is ascribed to a state diffusion region depending on whether political institutions within that territory originated internally or externally. If the state was internally originated, then, if the state is adjacent to a pristine state or close to it 
(in terms of physical distance or time of emergence), or it presents similar characteristics in terms of the patterns of political organization with that pristine state, then it is assigned to the diffusion region around that pristine state. One example is that of internally originated states in South-East Asia, which have been assigned to the South Asia region of diffusion, as they present the diffuse model of polities called "mandala states" which originated from India (these are states defined by a diffuse pattern of political control, with multiple local polities gravitating around a center of political power, but without a clear territorial demarcation of the overarching state). If a state is externally-originated, it is assigned to the diffusion region of the state it was colonised/conquered by. Most externally-originated states are originally formed by colonization by European powers. The latter are all assigned to the Western region of diffusion, having been plausibly influenced by the state development in Mesopotamia. Hence, the territories they colonized have states assigned to the same Western region. Within state diffusion regions, distances to pristine state are calculated as the length of the shortest curve (geodetic distance in $\mathrm{km}$ ) between the centroid of each country and the initiation point of its assigned pristine state: Uruk, Erlitou, Mohenjo Daro, Chavin, Monte Alban, and Hierakonpolis (e.g. the distance from the centroid of the UK to Uruk is around $4559 \mathrm{~km})$.

Number of thousand years before present for appearance of first state or proto-state, transition to reliance on agriculture, habitation by modern humans and state diffusion regions, are listed for our sample of countries in Table A1.

\section{Additional data - Geographical variables}

Landlocked. This is a dummy variable equal to 1 if the country is landlocked.

Absolute latitude. This is the absolute value of the country's centroid latitude. The variable was retrieved from the Portland Physical Geography dataset.

Distance to coast and river. This variable represents the mean distance to the nearest coastline or sea-navigable river, measured in kilometers. The variable was retrieved from the Portland Physical Geography dataset.

Mean elevation. The mean elevation above sea level is measured in meters. The variable was retrieved from the Portland Physical Geography dataset. The original source is NOAA's National Geophysical Data Center. 
Temperature. This is a mean across the average monthly temperature over time (1961-1990) in 1-degree resolution grids within a country. This variable was retrieved from Ashraf and Galor (2013), whose source is the G-ECON project (Nordhaus 2006).

Precipitation. This is a mean across the average monthly precipitation over time (1961-1990) in 1-degree resolution grids within a country. This variable was retrieved from Ashraf and Galor (2013), whose source is the G-ECON project (Nordhaus 2006).

Malaria (percentage population at risk). This variable represents the level of risk of contracting malaria (measured by the percentage population in 1994 in areas of high risk of contracting malaria, times the share of cases in the country involving fatal species of P. Falciparum). The original data was constructed by Gallup and Sachs (2001).

\section{Details on construction of Time since first human settlement}

The variable called Origtime by Ahlerup and Olsson (2012) attempts to measure the number of years before year $2000 \mathrm{CE}$ when modern humans first come to live within the territory of each country of year 2000. Dates of human arrival were based on Oppenheimer (2003) with judgments made on assignment of years to countries when required. For the present paper, we attempt to update estimated dates of human arrival maintaining Oppenheimer's hypothesis of a coastal route through southern Arabia which led to the peopling of coastal Asia before that of other parts of the world outside of Africa, home to modern humans prior to their exit and dispersion to other continents. Updates follow mainly the ideas in a set of papers and chapters recommended in personal communication by Oppenheimer, in particular Soares et al. (2009), Oppenheimer (2012a, 2012b, 2014).

Changes in origtime values from those shown in Ahlerup and Olsson and the principles upon which we base them are as follows:

1. Ahlerup and Olsson assign value 160,000 to Ethiopia and Kenya and 135,000 to all remaining mainland sub-Saharan African countries. Although Ethiopia and Kenya continue to be viewed as likely locations for emergence of anatomically modern humans $(\mathrm{AMH})$ in the period between 150,000 and 200,000 years ago, evidence for AMH has been found in other parts of the continent during that period, and there appears to be no agreement on when AMH of mtDNA haplogroups other than 
L3 first lived at each sub-Saharan location (see for example Hammer et al. (2011), and Soares et al. (2012)). Accordingly, we decided to retain the number 135,000 as a rough date for fully modern human presence in sub-Saharan Africa as a whole, dropping differentiation of Ethiopia and Kenya from the other sub-Saharan countries. (In our paper, we also report a robustness test in which a more recent time, 90,000 years ago, is assigned to all sub-Saharan African countries. Athough some anthropologists argue that AMH appear to have been present in Africa more than 200,000 years ago, questions have been raised as to whether the anatomically modern features of the earliest AMH could mask subtle differences in cognitive and social traits that changed closer to the time of the exit to other continents, so we checked whether our findings are sensitive to assuming later AMH appearance in Africa, and found little difference in results.)

2. Ahlerup and Olsson follow Oppenheimer (2003) in estimating that AMH traveled rapidly across coastal Asia shortly before the Toba eruption of about 74,000 years ago but Soares et al. (2009) and Oppenheimer (2012a, 2012b, 2014) now view the evidence as more likely pointing to an exit time about 72,000 years ago. This leads us to adjust origtime of Brunei, Iran, Oman, UAE, Malaysia, Singapore, Vietnam, and Indonesia from 75kya to 72kya. Ahlerup and Olsson put Yemen, the first country reached on the southern exit route, at $85 \mathrm{kya}$, but for consistency with the new sources, we also place Yemen at $72 \mathrm{kya}$. We reconsider arrival at Taiwan, an island which lies at the end of the suggested coastal route, because Oppenheimer (2012a, 2012b, 2014) now puts arrival in China proper at about 67.5kya, and does not explicitly estimate an arrival time for Taiwan. We adopt a more conservative $60 \mathrm{kya}$ for that island nation.

3. With respect to countries of the Middle East/West Asia/Fertile Crescent that are not located along the southern Asian coastal route beginning at Yemen, Soares et al. and Oppenheimer recognize the archeological and fossil evidence of probable AMH presence in many locations between 90,000 and 130,000 years ago, but they interpret the archeological and genetic evidence as suggesting that bands of AMH which exited Africa prior to the decisive southern route exit for which their most likely dating is $72 \mathrm{kya}$ died out (with possible interbreeding with Neanderthal and Denisovan pre-AMH species not ruled out, but with probable replacement by Neanderthals after 90kya). Their argument 
hinges on the idea that all modern humans outside Africa until recent centuries were genetically descended from the $\mathrm{M}$ and $\mathrm{N}$ clades of the L3 mtDNA haplogroup, and that markers for these are associated with the later (ca. 72kya) southern exiters but not the earlier AMH dwellers in the Middle East. Consistent with this interpretation and dates provided in Oppenheimer (2003), Ahlerup and Olsson put AMH arrival in what are now Egypt, Israel, Jordan, Lebanon, Syria, and Saudi Arabia at 40kya, although they set AMH arrival in Iraq and Turkey at $52 \mathrm{kya}$ as part of a migration of Asian populations westward through countries-of-today that include Armenia, Azerbaijan, and Georgia. We recognize that dating AMH arrival in the heart of the Middle East/West Asia/Fertile Crescent to so late a date as 40kya is certain to be criticized in view of the abundant evidence for modern human presence at much earlier times. As a modest bow in the direction of such views, we amend the estimates for Egypt, Israel, Jordan, Lebanon, Syria and Saudia Arabia to match those for Iraq and Turkey at 52kya. We also assign the 52kya value to Qatar and Kuwait, assuming that these territories lying north of the most southern route across Asia were skipped over by a water passage across the Persian Gulf at 72kya, but then populated at the same time as Saudi Arabia and Iraq. It is important to note that with the one possible exception of applying the 52kya dating to these Middle Eastern countries, our guiding principles are (a) to date AMH arrival based on the interpretation that only arrival of individuals descended from the decisive exiting group of ca. 72kya belonging to $\mathrm{M}$ and $\mathrm{N}$ clades of L3 mtDNA haplogroup are to be counted outside of sub-Saharan Africa, and (b) to settle on a single compromise date for sub-Saharan Africa itself due to the lack of consensus about defining the transition date to fully modern humans, identifying exactly where transitional groups lived, and dating their dispersal within, SSA itself. We also note that it seems quite possible to us that using a date older than 40kya for the listed Middle Eastern countries will ultimately prove not to be an exception, i.e. it is not a stretch to think that evidence of northward migration by descendants of southern route exiters, or of a more northerly exit of related $\mathrm{M}$ and $\mathrm{N}$ clade members, might appear in coming years.

4. Ahlerup and Olsson follow Oppenheimer's assumption that although descendants of the AMH groups exiting Africa to what is now Yemen reached Southeast Asia very rapidly before the Toba eruption, no early 
humans survived the environmental catastrophe that followed in South Asia. For this reason, Bangladesh, Burma, Cambodia and Thailand receive a later date (65kya), and India, Pakistan, and Sri Lanka a still later one (52kya), in Ahlerup and Olsson, based on the assumption of their repopulation via westward migrations from the more eastern coastal countries including Malaysia. Now that a pre-Toba exit from Africa by AMH is considered to be less likely by Oppenheimer and his collaborators, we think it better to acknowledge that the bands taking a coastal route to Malaysia, Indonesia and Vietnam from Yemen, Oman and Iran must have passed through Pakistan, India, Bangladesh and Cambodia in the same era, ca. $72 \mathrm{kya}$, and that the failure of the first residents from this group to leave archeological evidence that has been uncovered and accepted as of today is not adequate reason to override the presumption that AMH resided in those countries at least as early as in Malaysia, Indonesia and Vietnam. Hence, we set arrival dates for Pakistan, India, Bangladesh, Burma and Cambodia at the same $72 \mathrm{kya}$ value as used for Malaysia, Indonesia and Vietnam. ${ }^{2}$ We do not, however, make the same assumption for Sri Lanka, since it is an Island, and no specific evidence for its occupation as early as $72 \mathrm{kya}$ seems to have been adduced. We instead follow Ranaweera et al. (2014) and assign a date of $37 \mathrm{kya}$ to AMH habitation in Sri Lanka. ${ }^{3}$

\footnotetext{
${ }^{2}$ Note that Oppenheimer in no way disputes that the descendants of the original exiters via Yemen proceeded by scavenging along the coasts of what are now Pakistan, India, Bangladesh, etc. Nor does Oppenheimer now express a strong conviction that archeological evidence of their presence along those coasts is unlikely ever to be found. Even if descendants of the bands that reached Southeast Asia via South Asia had fully died out and been fully replaced by westward migrants as much as twenty thousand years later, the South Asian case differs from the of Middle East countries like Egypt, Israel and Saudi Arabia in that the early AMH who lived in the latter countries around 90kya and earlier are assumed by Oppenheimer and collaborators to have left no genetic legacy, whereas the early AMH who are believed to have lived on the coasts of what are now Pakistan, India, etc. around 72kya would have been members of the same genetic branch $(\mathrm{N}$ and $\mathrm{M}$ clades of mtDNA haplogroup L3) that populated the entire world beyond sub-Saharan Africa beginning about 72kya.

${ }^{3}$ Ranaweera et al. focus on establishing the genetic connections among different subpopulations in Sri Lanka, but state "Archaeological records of human settlements on the island were conventionally attributed to four consecutive periods: the Paleolithic $(125,000-$ 37,000 YBP), the Mesolithic (37,000-2900 YBP), the protohistorical (2900-2500 YBP) and the historical (after $2500 \mathrm{YBP}$ ). Interestingly the oldest skeletal remains of anatomically
} 
5. Inland Southeast Asia: only one country-of-today in Southeast Asia cannot be assigned a date based on assumed migration of AMH from Yemen to as far away as Vietnam within a very short period of time. That exception is Laos, an entirely landlocked country. We assign Laos the same year as China, which Oppenheimer assumes to have been populated by south to north migration at about $67.5 \mathrm{kya}$.

6. We follow Oppenheimer (2012a, 2012b, 2014) in assigning estimate 55kya to Australia ${ }^{4}$, and Oppenheimer 2014 in assigning estimate 46 kya to Papua New Guina, both representing changes from Oppenheimer (2003) and Ahlerup and Olsson which used the estimate of 65kya for both countries.

7. Oppenheimer (2012a, 2012b) retains the estimate of 15kya for the mainland Western Hemisphere from Venezuela and Colombia northwards and of $12.5 \mathrm{kya}$ to the south of those countries, but appears to apply the 15kya estimate for all of North America, so we adjust the previous estimates of 22kya for Canada and the United States (which had been based on remarks about early Beringia settlement) to 15kya. Island countries off of the hemisphere's mainland retain their estimates of more recent settlement and are now joined by Trinidad and Tobago, adjusted from 15kya to $7.5 \mathrm{kya}$.

8. We adjusted the estimate for Poland which was shared with Baltic and other northern European countries Belgium, Denmark, Estonia, Finland, Ireland, Latvia, Lithuania, etc., to an earlier one, 25kya, which it now shares with Slovakia, Czeck Republic and Ukraine. We made this change on grounds that Poland extends further south and inland than the other countries of the northern European group, and because the much later estimate used for countries such as Denmark is also potentially misaligned relative to the dating of arrival in Germany at 45kya.

modern man (Homo sapiens) reported from the South Asian region, and dated tentatively to $37,000 \mathrm{YBP}$, were discovered from the cave site, Fahien-lena, on the island." Because the Paleolithic estimate range 125-37kya extends well before the 72kya exit from Africa assumed by Oppenheimer, and again given that Sri Lanka is an island that could conceivably have been passed by in the eastward migration from Yemen to Southeast Asia, we adopt $37 \mathrm{kya}$ as a conservative estimate.

${ }^{4}$ More specifically, Oppenheimer adopts the window 50 - 60kya for Australia in each paper. We accordingly adopt that periods midpoint. 
9. We adjusted the estimate for Madagascar from 1.3kya to 2 kya. 
Table A1: State Age, Transition to Agriculture, First Human Settlement and State Diffusion Region in 159 countries

\begin{tabular}{|c|c|c|c|c|c|}
\hline Country & Isocode & $\begin{array}{l}\text { First state } \\
\text { or proto-state } \\
\text { KYBP }\end{array}$ & $\begin{array}{l}\text { Transition to } \\
\text { agriculture } \\
\text { KYBP }\end{array}$ & $\begin{array}{l}\text { Settlement by } \\
\text { modern } \\
\text { humans, KYBP }\end{array}$ & $\begin{array}{l}\text { State } \\
\text { Diffusion } \\
\text { Region }\end{array}$ \\
\hline Afghanistan & AFG & 4.3 & 9 & 40 & Western \\
\hline Albania & ALB & 2.8 & 7.5 & 45 & Western \\
\hline Algeria & DZA & 2.7 & 4 & 40 & Western \\
\hline Angola & AGO & 0.65 & 1.25 & 135 & Western \\
\hline Armenia & ARM & 3.3 & 8 & 52 & Western \\
\hline Australia & AUS & 0.2 & 0.4 & 55 & Western \\
\hline Austria & AUT & 2.2 & 6.5 & 45 & Western \\
\hline Azerbaijan & AZE & 2.625 & 8 & 52 & Western \\
\hline Barbados & $\mathrm{BRB}$ & 0.373 & 1.7 & 6 & Western \\
\hline Belarus & BLR & 1.25 & 4.5 & 8 & Western \\
\hline Belgium & BEL & 2.05 & 5.5 & 8 & Western \\
\hline Benin & BEN & 0.375 & 3.1 & 135 & Western \\
\hline Bosnia and Herzegovina & $\mathrm{BIH}$ & 2.4 & 7 & 45 & Western \\
\hline Botswana & BWA & 0.9 & 1 & 135 & Western \\
\hline Brazil & BRA & 0.467 & 3.8 & 12.5 & Western \\
\hline Bulgaria & BGR & 2.516 & 7.5 & 45 & Western \\
\hline Burkina Faso & BFA & 0.55 & 2.9 & 135 & Western \\
\hline Burundi & BDI & 0.35 & 2.5 & 135 & Western \\
\hline Comoros & $\mathrm{COM}$ & 0.114 & 1.35 & 1.5 & Western \\
\hline Cameroon & CMR & 1.15 & 3 & 135 & Western \\
\hline Canada & $\mathrm{CAN}$ & 0.4 & 1.5 & 15 & Western \\
\hline Cape Verde & $\mathrm{CPV}$ & 0.55 & 0.538 & 0.5 & Western \\
\hline Central African Republic & CAF & 0.1 & 3 & 135 & Western \\
\hline Chad & TCD & 1.15 & 2.7 & 135 & Western \\
\hline Congo, Rep. & $\mathrm{COG}$ & 0.55 & 3 & 135 & Western \\
\hline Costa Rica & CRI & 0.45 & 2.5 & 15 & Western \\
\hline Cote d'Ivoire & CIV & 0.6 & 3.5 & 135 & Western \\
\hline Croatia & HRV & 2.4 & 7 & 45 & Western \\
\hline Cuba & CUB & 0.489 & 0.8 & 6 & Western \\
\hline Cyprus & CYP & 3.3 & 8.5 & 12 & Western \\
\hline Czech Republic & CZE & 1.182 & 6.5 & 25 & Western \\
\hline Democratic Rep. of Congo & ZAR & 0.55 & 3 & 135 & Western \\
\hline Denmark & DNK & 1.3 & 5.5 & 8 & Western \\
\hline Dominican Republic & DOM & 0.5 & 1.5 & 6 & Western \\
\hline Equatorial Guinea & GNQ & 0.506 & 3 & 135 & Western \\
\hline El Salvador & SLV & 0.472 & 3 & 15 & Western \\
\hline Estonia & EST & 0.763 & 3.7 & 8 & Western \\
\hline Ethiopia & ETH & 2.7 & 4 & 135 & Western \\
\hline
\end{tabular}




\begin{tabular}{|c|c|c|c|c|c|}
\hline Fiji & FJI & 0.126 & 3.5 & 3 & Western \\
\hline Finland & FIN & 0.75 & 3.5 & 8 & Western \\
\hline France & FRA & 2.6 & 7.5 & 45 & Western \\
\hline Gabon & GAB & 0.15 & 3 & 135 & Western \\
\hline Gambia, The & GMB & 0.5 & 3 & 135 & Western \\
\hline Georgia & GEO & 2.8 & 8 & 52 & Western \\
\hline Germany & DEU & 2 & 6 & 45 & Western \\
\hline Ghana & GHA & 0.75 & 3.5 & 135 & Western \\
\hline Greece & GRC & 4.5 & 8.5 & 45 & Western \\
\hline Grenada & GRD & 0.35 & 2 & 6 & Western \\
\hline Guinea & GIN & 0.65 & 3.25 & 135 & Western \\
\hline Guyana & GUY & 0.4 & 3.8 & 15 & Western \\
\hline Haiti & HTI & 0.5 & 1 & 6 & Western \\
\hline Hungary & HUN & 2.014 & 7.4 & 45 & Western \\
\hline Iceland & ISL & 0.75 & 1.13 & 1.2 & Western \\
\hline Iran & IRN & 5.2 & 9.5 & 72 & Western \\
\hline Iraq & IRQ & 5.5 & 10 & 52 & Western \\
\hline Ireland & IRL & 1.6 & 5 & 8 & Western \\
\hline Israel & ISR & 5 & 10.5 & 52 & Western \\
\hline Italy & ITA & 2.85 & 8 & 45 & Western \\
\hline Jamaica & JAM & 0.5 & 1 & 6 & Western \\
\hline Jordan & JOR & 4.7 & 10.5 & 52 & Western \\
\hline Kenya & $\mathrm{KEN}$ & 0.1 & 3.5 & 135 & Western \\
\hline Lebanon & $\mathrm{LBN}$ & 4.85 & 10.5 & 52 & Western \\
\hline Latvia & LVA & 0.763 & 3.7 & 8 & Western \\
\hline Lesotho & LSO & 0.176 & 1.5 & 135 & Western \\
\hline Liberia & LBR & 0.172 & 3.25 & 135 & Western \\
\hline Libya & LBY & 2.7 & 5.5 & 40 & Western \\
\hline Lithuania & LTU & 0.75 & 3.7 & 8 & Western \\
\hline Macedonia & MKD & 2.7 & 7.5 & 45 & Western \\
\hline Madagascar & $\mathrm{MDG}$ & 0.5 & 2 & 2 & Western \\
\hline Malawi & MWI & 0.52 & 1.8 & 135 & Western \\
\hline Mali & MLI & 1.25 & 3 & 135 & Western \\
\hline Mauritania & MRT & 1.25 & 3.5 & 135 & Western \\
\hline Mauritius & MUS & 0.279 & 0.362 & 0.5 & Western \\
\hline Moldova & MDA & 1.1 & 7 & 25 & Western \\
\hline Morocco & MAR & 2.6 & 3.5 & 40 & Western \\
\hline Mozambique & MOZ & 0.5 & 1.4 & 135 & Western \\
\hline Namibia & NAM & 0.116 & 1.25 & 135 & Western \\
\hline Netherlands & NLD & 2.027 & 6 & 8 & Western \\
\hline New Zealand & NZL & 0.15 & 0.8 & 1.2 & Western \\
\hline Nicaragua & NIC & 0.476 & 3 & 15 & Western \\
\hline Niger & NER & 0.7 & 4 & 135 & Western \\
\hline Nigeria & NGA & 1.25 & 2.7 & 135 & Western \\
\hline Norway & NOR & 1.2 & 5 & 8 & Western \\
\hline
\end{tabular}




\begin{tabular}{|c|c|c|c|c|c|}
\hline Panama & PAN & 0.5 & 2.4 & 15 & Western \\
\hline Papua New Guinea & PNG & 0.1 & 4 & 46 & Western \\
\hline Paraguay & PRY & 0.45 & 4 & 12.5 & Western \\
\hline Philippines & PHL & 0.5 & 5 & 17 & Western \\
\hline Poland & POL & 1.037 & 6 & 25 & Western \\
\hline Portugal & PRT & 2.2 & 6.5 & 40 & Western \\
\hline Romania & $\mathrm{ROM}$ & 2.35 & 7.5 & 45 & Western \\
\hline Russia & RUS & 1.138 & 5 & 25 & Western \\
\hline Rwanda & RWA & 0.45 & 2.5 & 135 & Western \\
\hline Sao Tome and Principe & STP & 0.52 & 0.52 & 0.5 & Western \\
\hline Saudi Arabia & SAU & 2.552 & 7.6 & 52 & Western \\
\hline Senegal & SEN & 0.95 & 3 & 135 & Western \\
\hline Serbia and Montenegro & YUG & 2.4 & 7.5 & 45 & Western \\
\hline Seychelles & $\mathrm{SYC}$ & 0.244 & 0.244 & 0.2 & Western \\
\hline Sierra Leone & SLE & 0.213 & 3.25 & 135 & Western \\
\hline Slovakia & SVK & 1.182 & 6.5 & 25 & Western \\
\hline Slovenia & SVN & 2.035 & 7 & 45 & Western \\
\hline South Africa & $\mathrm{ZAF}$ & 0.3 & 1.7 & 135 & Western \\
\hline Spain & ESP & 2.8 & 7.2 & 40 & Western \\
\hline Swaziland & SWZ & 0.23 & 1.5 & 135 & Western \\
\hline Sweden & SWE & 0.85 & 5.5 & 8 & Western \\
\hline Switzerland & $\mathrm{CHE}$ & 2.2 & 5.5 & 45 & Western \\
\hline Syrian Arab Republic & SYR & 4.6 & 10 & 52 & Western \\
\hline Tanzania & TZA & 0.497 & 2.5 & 135 & Western \\
\hline Tajikistan & TJK & 4.3 & 7 & 40 & Western \\
\hline Togo & TGO & 0.25 & 3.1 & 135 & Western \\
\hline Trinidad and Tobago & TTO & 0.4 & 2 & 7.5 & Western \\
\hline Tunisia & TUN & 2.75 & 4.5 & 40 & Western \\
\hline Turkey & TUR & 5 & 10 & 52 & Western \\
\hline Turkmenistan & TKM & 4.3 & 8 & 40 & Western \\
\hline Uganda & UGA & 0.45 & 3.5 & 135 & Western \\
\hline Ukraine & UKR & 1.15 & 6.5 & 25 & Western \\
\hline United Kingdom & GBR & 1.95 & 5.5 & 8 & Western \\
\hline United States & USA & 0.4 & 3.2 & 15 & Western \\
\hline Uruguay & URY & 0.3 & 3.6 & 12.5 & Western \\
\hline Uzbekistan & UZB & 4.3 & 6.5 & 40 & Western \\
\hline Venezuela & VEN & 0.5 & 3.8 & 15 & Western \\
\hline Yemen & YEM & 4 & 7.6 & 72 & Western \\
\hline Zambia & ZMB & 0.2 & 1.8 & 135 & Western \\
\hline Zimbabwe & ZWE & 0.15 & 1.4 & 135 & Western \\
\hline Guatemala & GTM & 2.5 & 3.5 & 15 & Central America \\
\hline Honduras & HND & 2 & 3 & 15 & Central America \\
\hline Mexico & MEX & 2.45 & 4.1 & 15 & Central America \\
\hline Brunei & $\mathrm{BRN}$ & 1.5 & 4 & 72 & East Asia \\
\hline China & $\mathrm{CHN}$ & 3.9 & 9 & 67.5 & East Asia \\
\hline
\end{tabular}




\begin{tabular}{llllll} 
Hong Kong, China & HKG & 2.2 & 5 &. & East Asia \\
Japan & JPN & 1.75 & 4.5 & 40 & East Asia \\
Kazakhstan & KAZ & 0.8 & 6.5 & 40 & East Asia \\
Korea, Rep. & KOR & 2.8 & 4.5 & 40 & East Asia \\
Kyrgyzstan & KGZ & 0.793 & 6.5 & 40 & East Asia \\
Mongolia & MNG & 2.209 & 5 & 40 & East Asia \\
Taiwan, China & OAN & 0.4 & 5.5 & 60 & East Asia \\
Vietnam & VNM & 3.5 & 6 & 72 & East Asia \\
Argentina & ARG & 0.525 & 3.8 & 12.5 & South America \\
Bolivia & BOL & 2.3 & 4 & 12.5 & South America \\
Chile & CHL & 0.525 & 4 & 12.5 & South America \\
Colombia & COL & 0.5 & 3.4 & 15 & South America \\
Ecuador & ECU & 0.6 & 4 & 12.5 & South America \\
Peru & PER & 2.9 & 4.3 & 12.5 & South America \\
Bangladesh & BGD & 1.25 & 5.5 & 72 & South Asia \\
Cambodia & KHM & 2 & 4.5 & 72 & South Asia \\
India & IND & 4.6 & 8.5 & 72 & South Asia \\
Indonesia & IDN & 1.35 & 4 & 72 & South Asia \\
Laos & LAO & 1.6 & 6 & 67.5 & South Asia \\
Malaysia & MYS & 1.8 & 4.5 & 72 & South Asia \\
Myanmar & MMR & 2.2 & 5 & 72 & South Asia \\
Nepal & NPL & 1.6 & 6 & 40 & South Asia \\
Pakistan & PAK & 4.6 & 9 & 72 & South Asia \\
Singapore & SGP & 0.65 & 4.5 & 72 & South Asia \\
Sri Lanka & LKA & 2.543 & 5 & 37 & South Asia \\
Thailand & THA & 1.45 & 5.5 & 72 & South Asia \\
Djibouti & DJI & 3.5 & 4 & 135 & Upper Egypt \\
Eritrea & ERI & 3.5 & 4 & 135 & Upper Egypt \\
Egypt & EGY & 5.2 & 7.2 & 52 & Upper Egypt \\
Somalia & SOM & 3.5 & 3.5 & 135 & Upper Egypt \\
Sudan & SDN & 5 & 6 & 135 \\
\hline
\end{tabular}

The table displays, for each of 159 modern-day countries in our sample, the state age as of $2000 \mathrm{CE}$ (time since a proto-state or full state emerged on the country's territory, in ky), assembled by Borcan, Olsson, and Putterman (2018), the time since transition to agriculture as of $2000 \mathrm{CE}$ (ky) assembled by Putterman with Trainor (2006 [revised 2018]), time since first human settlement as of $2000 \mathrm{CE}$ (ky) assembled by Ahlerup and Olsson (2012 [revised 2018]), and assigned state diffusion region.

\section{Further figures and tables}


Figure A1: Transition to Agriculture and State Emergence in Internally-Originated States.

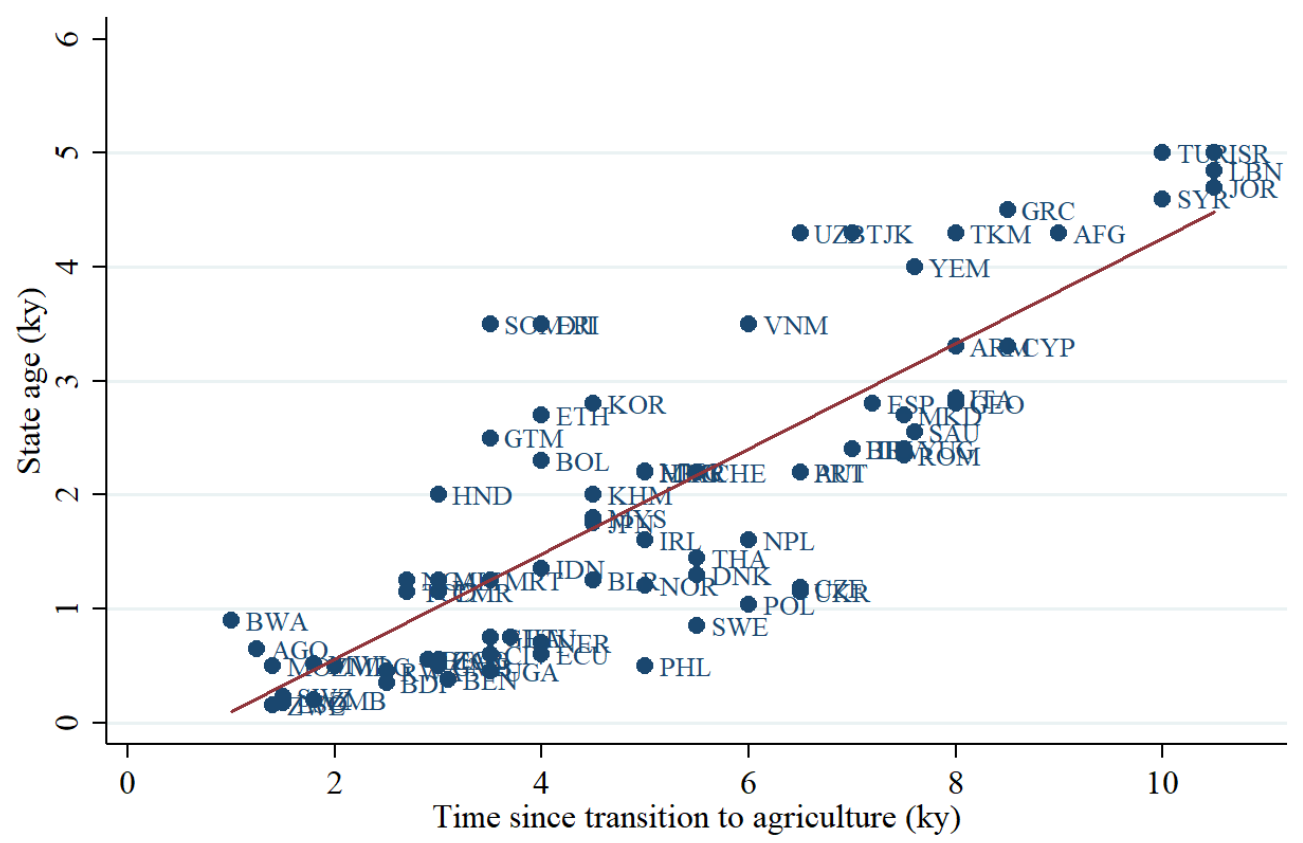

- State Age as of $2000 \mathrm{CE} \longrightarrow$ Fitted values

The graph shows the time elapsed since state emergence as of $2000 \mathrm{CE}$ plotted against the time since the transition to agriculture as of $2000 \mathrm{CE}$ in a sample of 79 countries, where states emerged as an indigenous development, excluding the 8 countries identified as places of emergence of pristine states. A linear fitted regression line has been included. The time since state emergence and whether a state is internally- originated are calculated and coded in Borcan, Olsson, and Putterman (2018). The time since the transition to agriculture is compiled by Putterman with Trainor (2006 [revised 2018]). 
Figure A2: Transition to Agriculture and State Emergence in Externally-Originated States.

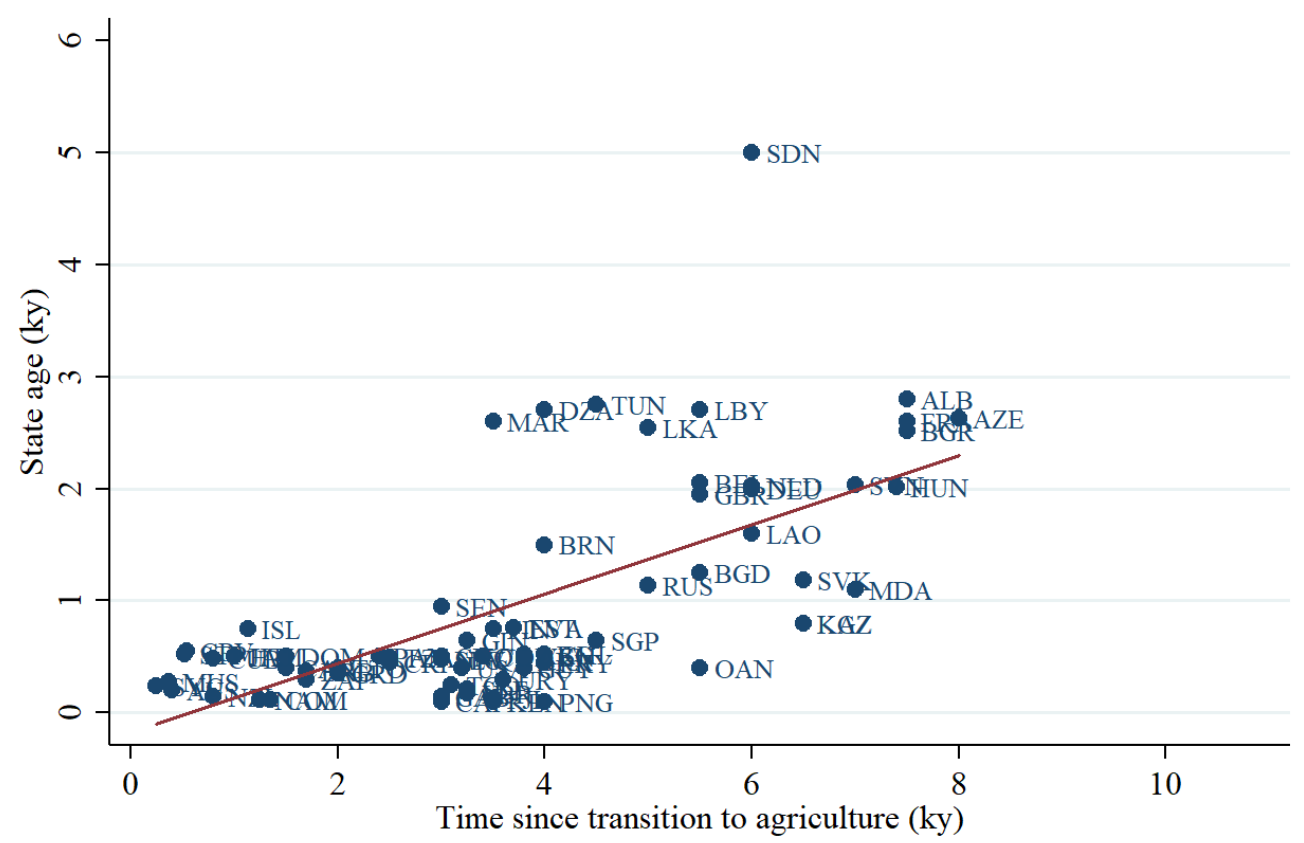

- State Age as of $2000 \mathrm{CE} \longrightarrow$ Fitted values

The graph shows the time elapsed since state emergence as of $2000 \mathrm{CE}$ plotted against the time since the transition to agriculture as of $2000 \mathrm{CE}$ in a sample of 72 countries where states emerged through conquest or substantial influence by a pre-existing state. A linear fitted regression line has been included. The time since state emergence and whether a state is externally-originated are calculated and coded in Borcan, Olsson, and Putterman (2018). The time since the transition to agriculture is compiled by Putterman with Trainor (2006 [revised 2018]). 
Figure A3: State age and time since transition to agriculture in non-pristine states; fullstates definition

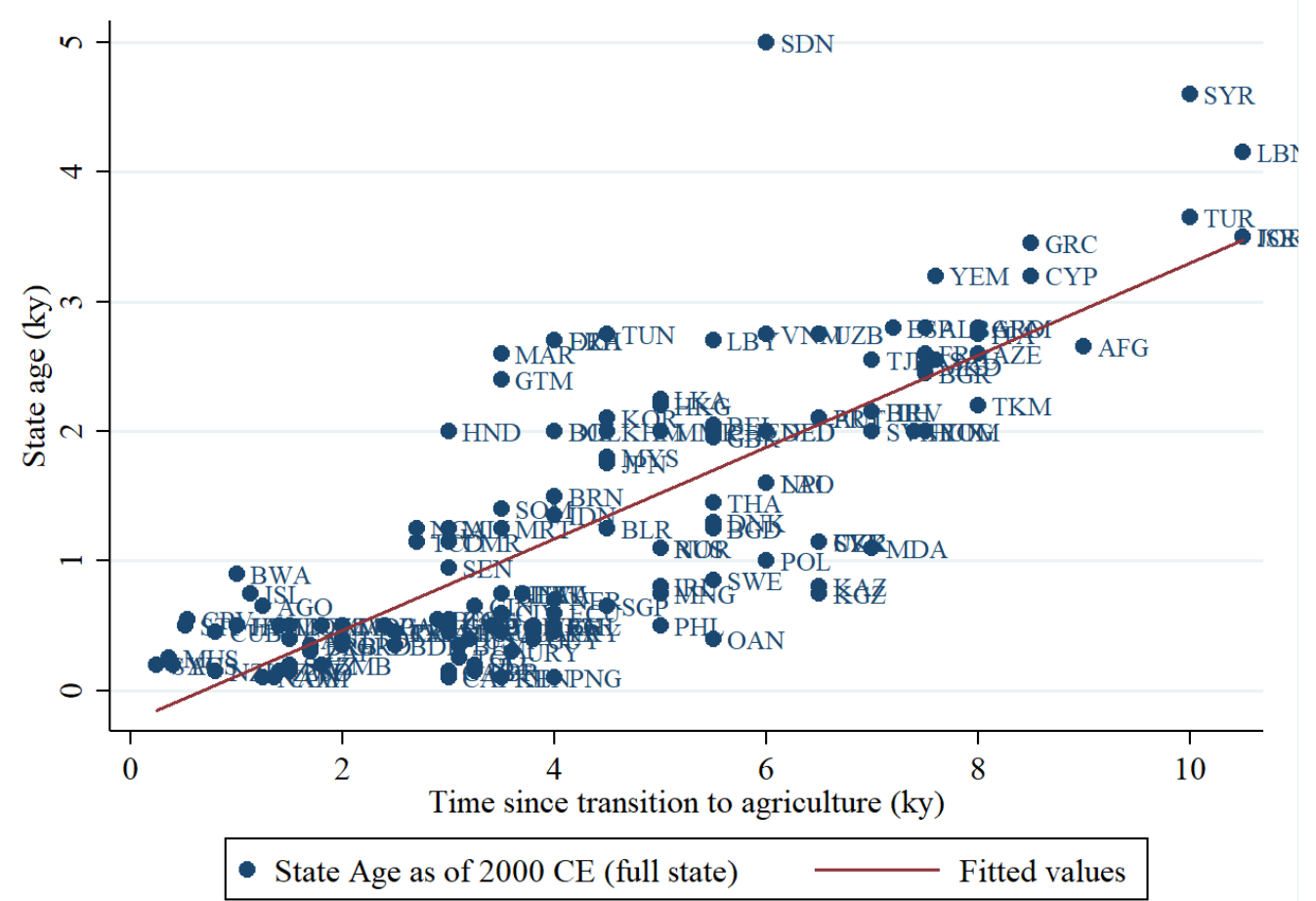

The graph shows the time elapsed since full state emergence as of $2000 \mathrm{CE}$ plotted against the time since the transition to agriculture in $2000 \mathrm{CE}$ in a sample of 151 countries, excluding the 8 countries identified as places of emergence of pristine states. This figure corresponds to Figure 1B of our paper except that it uses first full state instead of first proto-state as time of state emergence. A linear fitted regression line has been included. The time since state emergence and whether a state is externally-originated are calculated and coded in Borcan, Olsson, and Putterman (2018). The time since the transition to agriculture is compiled by Putterman with Trainor (2006 [revised 2018]). 
Table A2: State Age (full-state) and the Transition to Agriculture in Pristine States.

\begin{tabular}{lcccc}
\hline \hline & \multicolumn{5}{c}{ State Age } \\
\hline & $(1)$ & $(2)$ & $(3)$ & $(4)$ \\
Time since agriculture (ky) & & & & \\
& $0.338^{* *}$ & $0.751^{*}$ & 0.477 & $0.572^{* * *}$ \\
Time since first human settlement (ky) & $(0.112)$ & $(0.328)$ & $(0.497)$ & $(0.022)$ \\
& & -0.051 & & \\
Observations & & $(0.026)$ & & \\
R-squared & 8 & 8 & 8 & 8 \\
Controls & 0.331 & 0.510 & 0.566 & 0.998 \\
\hline
\end{tabular}

The table presents OLS regression estimates of the relationship between time since full state emergence as of $2000 \mathrm{CE}$ and time since the agriculture transition in 8 countries identified as places of emergence of pristine states. It parallels Table 1 of the paper, but calculates State age as dependent variable based on first appearance of a full state rather than of a proto-state or full state. In column 1 we present the unconditional estimate, in columns 2-4 we control for historical and geographical characteristics (column 2: country centroid absolute latitude, column 3: we add distance to coast and rivers and average elevation, column 4: we add precipitation, average temperature and percentage of people at risk of malaria to the controls of column 2, leaving out the controls added in column 3). The time since state emergence is calculated and coded in Borcan, Olsson, and Putterman (2018). The time since the transition to agriculture is compiled by Putterman with Trainor (2006 [revised 2018]). The time since first human settlement is the updated version of the data originally coded by Ahlerup and Olsson (2012) and it represents the time in millennia since initial uninterrupted settlement by modern humans (as of $2000 \mathrm{CE}$ ). The geographic and climatic controls and historical variables' construction is detailed in the Additional data subsection of this Appendix. Robust standard errors in parentheses. ${ }^{* * *} \mathrm{p}<0.01,{ }^{* *}$ $\mathrm{p}<0.05,{ }^{*} \mathrm{p}<0.1$ 
Table A3: State Age (full-state) and the Transition to Agriculture in Non-Pristine States - IV estimates

\begin{tabular}{lccc}
\hline \hline & \multicolumn{3}{c}{ State Age } \\
\hline & $(1)$ & $(2)$ & $(3)$ \\
Time since agriculture (ky) & & \\
& $0.351^{* * *}$ & $0.281^{* * *}$ & $0.356^{* * *}$ \\
Distance to pristine state & $(0.027)$ & $(0.042)$ & $(0.070)$ \\
& & $-0.077^{* * *}$ & -0.039 \\
Time since first human settlement (ky) & & $(0.025)$ & $(0.050)$ \\
& & -0.000 & -0.000 \\
& & $(0.001)$ & $(0.002)$ \\
Observations & 151 & 150 & 123 \\
R-squared & 0.616 & 0.648 & 0.775 \\
Controls & No & No & Yes \\
Diffusion Region & No & No & Yes \\
First stage F-statistic & 103.44 & 62.37 & 22.51 \\
Wooldridge's test statistic & $1.12 \mid .57$ & $2.24 \mid .33$ & $.56 \mid .76$ \\
\hline
\end{tabular}

The table presents two-stage least squares regression estimates of the relationship between the time since full state emergence and the time since transition to agriculture, in 151 countries, excluding 8 countries identified as places of emergence of pristine states. It parallels Table 2 of the paper, but calculates State age as dependent variable based on first appearance of a full state rather than of a proto-state or full state. We instrument the time since the transition to agriculture with biogeography and geography. State Age was assembled by Borcan, Olsson, and Putterman (2018) and it represents the time elapsed since state emergence as of $2000 \mathrm{CE}$ (in millennia). Plants and animals represent the number of domesticable plants and animals in 10000 BCE in different regions of the world (Eurasia, India and Far East, South-East Asia, Central America and Africa, North and South America, Oceania), and they were compiled by Hibbs and Olsson (2004). Geography is an index of geographical characteristics critical for the emergence and diffusion of agriculture: climate, latitude and East-West continental axis and continent size, and it was compiled by Olsson and Hibbs (2005). Agyears (the time since the transition to agriculture as of $2000 \mathrm{CE}$ ) was assembled by Putterman with Trainor (2006 [revised 2018]). The time since first human settlement is the updated version of the data originally coded by Ahlerup and Olsson (2012) and it represents the time in millennia since initial uninterrupted settlement by modern humans (as of $2000 \mathrm{CE}$ ). Distances to pristine state are calculated as the length of the shortest curve between the centroid of each country and the centroid of its assigned pristine state (the region from which state diffusion into the territory of the country in question is most likely to have originated). The geographic and climatic controls and historical variables' construction is detailed in the Additional data subsection of this Appendix. Robust standard errors in parentheses. ${ }^{* * *} \mathrm{p}<0.01,{ }^{* *}$ $\mathrm{p}<0.05,{ }^{*} \mathrm{p}<0.1$ 
Table A4: State Age (full-state) and the Transition to Agriculture in Non-Pristine States - IV estimates: Internally vs. Externally Originated States

\begin{tabular}{lcccc}
\hline \hline & \multicolumn{4}{c}{ State Age } \\
& Internally-Originated Externally-Originated \\
\hline & $(1)$ & $(2)$ & $(3)$ & $(4)$ \\
Time since agriculture (ky) & & & \\
& $0.317^{* * *}$ & $0.441^{* * *}$ & $0.347^{* * *}$ & $0.305^{* * *}$ \\
Distance to pristine state & $(0.032)$ & $(0.092)$ & $(0.050)$ & $(0.079)$ \\
& & -0.030 & & $-0.077^{*}$ \\
Time since first human settlement $(\mathrm{ky})$ & & $(0.109)$ & & $(0.041)$ \\
& & 0.004 & & $-0.006^{* * *}$ \\
& & $(0.004)$ & & $(0.002)$ \\
Observations & 79 & 71 & 72 & 52 \\
R-squared & 0.689 & 0.806 & 0.426 & 0.869 \\
Controls & No & Yes & No & Yes \\
Diffusion Region & No & Yes & No & Yes \\
First stage F-statistic & 70.18 & 15.3 & 44.41 & 8.80 \\
Wooldridge's test statistic & $.67 \mid .71$ & $2.14 \mid .34$ & $6.21 \mid .04$ & $8.58 \mid .01$ \\
\hline
\end{tabular}

The table presents two-stage least squares regression estimates of the relationship between the time since full state emergence and the time since transition to agriculture, in internally and externally originated states, excluding 8 countries identified as places of emergence of pristine states. It parallels Table 3 of the paper, but calculates State age as dependent variable based on first appearance of a full state rather than of a proto-state or full state. We instrument the time since the transition to agriculture with biogeography and geography. State Age was assembled by Borcan, Olsson, and Putterman (2018) and it represents the time elapsed since state emergence as of $2000 \mathrm{CE}$ (in millennia). Plants and animals represent the number of domesticable plants and animals in $10000 \mathrm{BCE}$ in different regions of the world (Eurasia, India and Far East, South-East Asia, Central America and Africa, North and South America, Oceania), and they were compiled by Hibbs and Olsson (2004). Geography is an index of geographical characteristics critical for the emergence and diffusion of agriculture: climate, latitude and East-West continental axis and continent size, and it was compiled by Olsson and Hibbs (2005). Agyears (the time since the transition to agriculture as of $2000 \mathrm{CE}$ ) was assembled by Putterman with Trainor (2006 [revised 2018]). The time since first human settlement is the updated version of the data originally coded by Ahlerup and Olsson (2012) and it represents the time in millennia since initial uninterrupted settlement by modern humans (as of $2000 \mathrm{CE}$ ). Distances to pristine state are calculated as the length of the shortest curve between the centroid of each country and the centroid of its assigned pristine state (the region from which state diffusion into the territory of the country in question is most likely to have originated). The geographic and climatic controls and historical variables' construction is detailed in the Additional data subsection of this Appendix. Robust stgndard errors in parentheses. ${ }^{* * *} \mathrm{p}<0.01,{ }^{* *}$ $\mathrm{p}<0.05,{ }^{*} \mathrm{p}<0.1$ 
Table A5: State Age, biogeography, geography and the transition to agriculture in nonpristine states

\begin{tabular}{lccc}
\hline \hline & \multicolumn{3}{c}{ State Age } \\
\hline & $(1)$ & $(2)$ & $(3)$ \\
Plants & 0.014 & 0.009 & -0.010 \\
& $(0.012)$ & $(0.012)$ & $(0.033)$ \\
Animals & $0.141^{* * *}$ & -0.012 & 0.091 \\
& $(0.045)$ & $(0.052)$ & $(0.109)$ \\
Geography & 0.020 & -0.201 & 0.021 \\
& $(0.139)$ & $(0.153)$ & $(0.150)$ \\
Time since agriculture (ky) & & $0.472^{* * *}$ & $0.311^{* * *}$ \\
& & $(0.057)$ & $(0.046)$ \\
Observations & & & \\
R-squared & 151 & 151 & 123 \\
Controls & 0.375 & 0.616 & 0.827 \\
Diffusion Region FE & No & No & Yes \\
& No & No & Yes \\
\hline
\end{tabular}

The table presents OLS regression estimates of the relationship between time since state emergence as of $2000 \mathrm{CE}$ and biogeography and geography in 151 countries, excluding 8 countries identified as places of emergence of pristine states. State Age was assembled by Borcan, Olsson, and Putterman (2018) and it represents the time elapsed since state emergence as of $2000 \mathrm{CE}$ (in millennia). Plants and animals represent the number of domesticable plants and animals in $10000 \mathrm{BCE}$ in different regions of the world (Eurasia, India and Far East, South-East Asia, Central America and Africa, North and South America, Oceania), and they were compiled by Hibbs and Olsson (2004). Geography is an index of geographical characteristics critical for the emergence and diffusion of agriculture: climate, latitude and East-West continental axis and continent size, and it was compiled by Olsson and Hibbs (2005). Agyears (the time since the transition to agriculture as of 2000 CE) was assembled by Putterman with Trainor (2006 [revised 2018]). The time since first human settlement is the updated version of the data originally coded by Ahlerup and Olsson (2012) and it represents the time in millennia since initial uninterrupted settlement by modern humans (as of $2000 \mathrm{CE}$ ). The geographic and climatic controls and historical variables' construction is detailed in the Additional data subsection of this Appendix. Robust standard errors in parentheses. ${ }^{* * *} \mathrm{p}<0.01,{ }^{* *} \mathrm{p}<0.05,{ }^{*} \mathrm{p}<0.1$ 
Table A6: State Age and the Transition to Agriculture in Non-Pristine States - IV first stage estimates

\begin{tabular}{lccc}
\hline \hline & \multicolumn{3}{c}{ Time since agriculture (ky) } \\
\hline & $(1)$ & $(2)$ & $(3)$ \\
Plants & 0.010 & 0.011 & -0.036 \\
& $(0.014)$ & $(0.014)$ & $(0.035)$ \\
Animals & $0.323^{* * *}$ & $0.322^{* * *}$ & $0.283^{*}$ \\
& $(0.046)$ & $(0.057)$ & $(0.163)$ \\
Geography & $0.468^{*}$ & 0.386 & $1.283^{* * *}$ \\
& $(0.245)$ & $(0.246)$ & $(0.288)$ \\
Distance to pristine state & & $-0.098^{* *}$ & $-0.222^{* *}$ \\
& & $(0.042)$ & $(0.091)$ \\
Time since first human settlement (ky) & & $0.005^{* *}$ & $-0.008^{*}$ \\
& & $(0.002)$ & $(0.004)$ \\
& & & \\
Observations & 151 & 150 & 123 \\
R-squared & 0.671 & 0.703 & 0.775 \\
Controls & No & No & Yes \\
Diffusion Region & No & No & Yes \\
\hline
\end{tabular}

Note: The table presents OLS regression estimates of the first stage in the IV regressions reported in Table 2 in the paper (time since transition to agriculture as the dependent variables, and the instruments as the main independent variables). State Age was assembled by Borcan, Olsson, and Putterman (2018) and it represents the time elapsed since state emergence as of $2000 \mathrm{CE}$ (in millennia). Agyears (millennia since the transition agriculture as of $2000 \mathrm{CE}$ ) was assembled by Putterman with Trainor (2006 [revised 2018]). The time since first human settlement is the updated version of the data originally coded by Ahlerup and Olsson (2012) and it represents the time in millennia since initial uninterrupted settlement by modern humans (as of $2000 \mathrm{CE}$ ). Distances to pristine state are calculated as the length of the shortest curve between the centroid of each country and the centroid of its assigned pristine state (the region from which state diffusion into the territory of the country in question is most likely to have originated). The geographic and climatic controls and historical variables' construction is detailed in the Additional data subsection of this Appendix. Robust standard errors in parentheses. ${ }^{* *} \mathrm{p}<0.01,{ }^{* *}$ $\mathrm{p}<0.05,{ }^{*} \mathrm{p}<0.1$ 
Table A7: State Age and the Transition to Agriculture in Non-Pristine States - OLS estimates

\begin{tabular}{lccc}
\hline \hline & \multicolumn{3}{c}{ State Age } \\
\hline & $(1)$ & $(2)$ & $(3)$ \\
Time since agriculture (ky) & & \\
& $0.430^{* * *}$ & $0.366^{* * *}$ & $0.335^{* * *}$ \\
Distance to pristine state & $(0.025)$ & $(0.030)$ & $(0.040)$ \\
& & $-0.085^{* * *}$ & $-0.111^{* * *}$ \\
Time since first human settlement (ky) & & $(0.019)$ & $(0.041)$ \\
& & $(0.000$ & $-0.003^{*}$ \\
& & & $(0.002)$ \\
Observations & 151 & 150 & 123 \\
R-squared & 0.609 & 0.643 & 0.824 \\
Controls & No & No & Yes \\
Diffusion Region & No & No & Yes \\
\hline
\end{tabular}

Note: The table presents OLS regression estimates of the relationship between time since state emergence as of $2000 \mathrm{CE}$, and time since transition to agriculture in 151 countries, excluding 8 countries identified as places of emergence of pristine states. State Age was assembled by Borcan, Olsson, and Putterman (2018) and it represents the time elapsed since state emergence as of $2000 \mathrm{CE}$ (in millennia). Agyears (time since the transition of agriculture as of $2000 \mathrm{CE}$ ) was assembled by Putterman with Trainor (2006 [revised 2018]). The time since first human settlement is the updated version of the data originally coded by Ahlerup and Olsson (2012) and it represents the time in millennia since initial uninterrupted settlement by modern humans (as of $2000 \mathrm{CE}$ ). Distances to pristine state are calculated as the length of the shortest curve between the centroid of each country and the centroid of its assigned pristine state (the region from which state diffusion into the territory of the country in question is most likely to have originated). The geographic and climatic controls and historical variables' construction is detailed in the Additional data subsection of this Appendix. Robust standard errors in parentheses. ${ }^{* * *} \mathrm{p}<0.01,{ }^{* *}$ $\mathrm{p}<0.05,{ }^{*} \mathrm{p}<0.1$ 
Table A8: Robustness: State Age and the Transition to Agriculture in Non-Pristine States - IV estimates, two instruments

\begin{tabular}{lccc}
\hline \hline & \multicolumn{3}{c}{ State Age } \\
\hline & $(1)$ & $(2)$ & $(3)$ \\
Time since agriculture (ky) & & \\
& $0.414^{* * *}$ & $0.322^{* * *}$ & $0.475^{* * *}$ \\
Distance to pristine state & $(0.035)$ & $(0.049)$ & $(0.144)$ \\
& & $-0.103^{* * *}$ & -0.024 \\
Time since first human settlement (ky) & & $(0.028)$ & $(0.095)$ \\
& & -0.000 & -0.000 \\
& & & \\
& & & \\
Observations & 151 & 150 & 123 \\
R-squared & 0.608 & 0.639 & $0.001)$ \\
Controls & No & No & Yes \\
Diffusion Region & No & No & Yes \\
First stage F-statistic & 151.27 & 87.74 & 7.12 \\
Wooldridge's test statistic & $.27 \mid .6$ & $.95 \mid .33$ & $.05 \mid .82$ \\
\hline
\end{tabular}

Note: The table presents two-stage least squares regression estimates of the relationship between the time since state emergence and the time since transition to agriculture, in 151 countries, excluding 8 countries identified as places of emergence of pristine states. It parallels Table 2 in the paper, with the distinction that the instruments used in Table 2 estimations are biogeography (domesticable plants and animals) and geography, whereas the latter instrument is dropped from estimations in the current table. State Age is based on the emergence of either a proto-state or a full state and was assembled by Borcan, Olsson, and Putterman (2018) and it represents the time elapsed since state emergence as of $2000 \mathrm{CE}$ (in millennia). Plants and animals represent the number of domesticable plants and animals in 10000 BCE in different regions of the world (Eurasia, India and Far East, South-East Asia, Central America and Africa, North and South America, Oceania), and they were compiled by Hibbs and Olsson (2004). Agyears (time since the transition of agriculture as of $2000 \mathrm{CE}$ ) was assembled by Putterman with Trainor (2006 [revised 2018]). The time since first human settlement is the updated version of the data originally coded by Ahlerup and Olsson (2012) and it represents the time in millennia since initial uninterrupted settlement by modern humans (as of $2000 \mathrm{CE}$ ). Distances to pristine state are calculated as the length of the shortest curve between the centroid of each country and the centroid of its assigned pristine state (the region from which state diffusion into the territory of the country in question is most likely to have originated). The geographic and climatic controls and historical variables' construction is detailed in the Additional data subsection of this Appendix. Robust standard errors in parentheses. ${ }^{* * *} \mathrm{p}<0.01,{ }^{* *}$ $\mathrm{p}<0.05,{ }^{*} \mathrm{p}<0.1$ 
Table A9: Robustness: State Age and the Transition to Agriculture in Non-Pristine States - IV estimates, alternative geography measure

\begin{tabular}{lccc}
\hline \hline & \multicolumn{3}{c}{ State Age } \\
\hline & $(1)$ & $(2)$ & $(3)$ \\
Time since agriculture (ky) & & \\
& $0.410^{* * *}$ & $0.315^{* * *}$ & $0.425^{* * *}$ \\
Distance to pristine state & $(0.034)$ & $(0.048)$ & $(0.081)$ \\
& & $-0.106^{* * *}$ & -0.055 \\
Time since first human settlement (ky) & & $(0.028)$ & $(0.061)$ \\
& & -0.000 & -0.002 \\
& & & \\
& & & \\
Observations & 151 & 150 & 123 \\
R-squared & 0.608 & 0.638 & 0.817 \\
Controls & No & No & Yes \\
Diffusion Region & No & No & Yes \\
First stage F-statistic & 102.1 & 62.13 & 20.7 \\
Wooldridge's test statistic & $3.7 \mid .16$ & $3.11 \mid .21$ & $.49 \mid .78$ \\
\hline
\end{tabular}

The table presents two-stage least squares regression estimates of the relationship between the time since state emergence and the time since transition to agriculture, in 151 countries, excluding 8 countries identified as places of emergence of pristine states. It parallels Table 2 in the paper, with the distinction that the geography instrument in Table 2 contains variation from island axes which are different from continent axes, whereas here island axes are identical to their continent axes. State Age is based on the emergence of either a proto-state or a full state and was assembled by Borcan, Olsson, and Putterman (2018) and it represents the time elapsed since state emergence as of $2000 \mathrm{CE}$ (in millennia). Plants and animals represent the number of domesticable plants and animals in 10000 BCE in different regions of the world (Eurasia, India and Far East, South-East Asia, Central America and Africa, North and South America, Oceania), and they were compiled by Hibbs and Olsson (2004). Agyears (time since the transition of agriculture as of 2000 CE) was assembled by Putterman with Trainor (2006 [revised 2018]). The time since first human settlement is the updated version of the data originally coded by Ahlerup and Olsson (2012) and it represents the time in millennia since initial uninterrupted settlement by modern humans (as of $2000 \mathrm{CE}$ ). Distances to pristine state are calculated as the length of the shortest curve between the centroid of each country and the centroid of its assigned pristine state (the region from which state diffusion into the territory of the country in question is most likely to have originated). The geographic and climatic controls and historical variables' construction is detailed in the Additional data subsection of this Appendix. Robust standard errors in parentheses. ${ }^{* * *} \mathrm{p}<0.01,{ }^{* *} \mathrm{p}<0.05,{ }^{*} \mathrm{p}<0.1$ 
Table A10: Robustness: State Age and the Transition to Agriculture in Non-Pristine States - IV estimates, interaction terms

\begin{tabular}{lccc}
\hline \hline & $(1)$ & $(2)$ & $(3)$ \\
& & & \\
& & & \\
& $0.410^{* * *}$ & $0.360^{* * *}$ & $0.402^{* * *}$ \\
Time since agriculture (ky) & $(0.034)$ & $(0.035)$ & $(0.075)$ \\
& & $-1.037^{* *}$ & -0.253 \\
Distance to pristine state & $(0.511)$ & $(0.500)$ \\
& & $0.096^{*}$ & 0.019 \\
Distance to pristine x & & $(0.051)$ & $(0.052)$ \\
Time since agriculture for pristine state & & $-0.225^{*}$ & $-0.816^{* * *}$ \\
Time since agriculture for pristine state & & $(0.130)$ & $(0.119)$ \\
& & 0.001 & -0.002 \\
Time since first human settlement & & $(0.001)$ & $(0.002)$ \\
& & \\
Observations & 151 & 150 & 123 \\
R-squared & 0.607 & 0.655 & 0.820 \\
Controls & No & No & Yes \\
Diffusion Region & No & No & Yes \\
First stage F-statistic & 103.44 & 75.61 & 22.03 \\
Wooldridge's test statistic & & \multicolumn{3}{c}{} \\
\hline
\end{tabular}

The table presents two-stage least squares regression estimates of the relationship between the time since state emergence and the time since transition to agriculture, in 151 countries, excluding 8 countries identified as places of emergence of pristine states. It parallels Table 2 in the paper, with the distinction that in this table's estimations we include the time since transition to agriculture in the assigned pristine state, as well as its interaction with the distance to that assigned pristine state. State Age is based on the emergence of either a proto-state or a full state and was assembled by Borcan, Olsson, and Putterman (2018) and it represents the time elapsed since state emergence as of $2000 \mathrm{CE}$ (in millennia). Plants and animals represent the number of domesticable plants and animals in 10000 BCE in different regions of the world (Eurasia, India and Far East, South-East Asia, Central America and Africa, North and South America, Oceania), and they were compiled by Hibbs and Olsson (2004). Agyears (time since the transition of agriculture as of 2000 CE) was assembled by Putterman with Trainor (2006 [revised 2018]). The time since first human settlement is the updated version of the data originally coded by Ahlerup and Olsson (2012) and it represents the time in millennia since initial uninterrupted settlement by modern humans (as of $2000 \mathrm{CE}$ ). Distances to pristine state are calculated as the length of the shortest curve between the centroid of each country and the centroid of its assigned pristine state (the region from which state diffusion into the territory of the country in question is most likely to have origifated). The geographic and climatic controls and historical variables' construction is detailed in the Additional data subsection of this Appendix. Robust standard errors in parentheses. ${ }^{* * *} \mathrm{p}<0.01,{ }^{* *} \mathrm{p}<0.05,{ }^{*} \mathrm{p}<0.1$ 
Table A11: State Age and the Transition to Agriculture in Non-Pristine States - IV estimates. Robustness test substituting distance from East Africa for time since first human settlement

\begin{tabular}{lccc}
\hline \hline & \multicolumn{3}{c}{ State Age } \\
\hline & $(1)$ & $(2)$ & $(3)$ \\
Time since agriculture (ky) & $0.410^{* * *}$ & $0.314^{* * *}$ & $0.410^{* * *}$ \\
& $(0.034)$ & $(0.049)$ & $(0.115)$ \\
Distance to pristine state & & $-0.109^{* * *}$ & -0.098 \\
& & $(0.031)$ & $(0.158)$ \\
Migratory distance from East Africa & & -0.001 & 0.024 \\
& & $(0.011)$ & $(0.057)$ \\
Observations & & & \\
R-squared & 151 & 150 & 123 \\
Controls & 0.607 & 0.649 & 0.820 \\
Diffusion Region & No & No & Yes \\
First stage F-statistic & No & No & Yes \\
Wooldridge's test statistic & 103.44 & 63.96 & 14.09 \\
& $1.87 \mid .39$ & $4.08 \mid .13$ & $1.19 \mid .55$ \\
\hline
\end{tabular}

The table presents two-stage least squares regression estimates of the relationship between the time since state emergence and the time since transition to agriculture, in 151 countries, excluding 8 countries identified as places of emergence of pristine states. It parallels Table 2 in the paper, with the distinction that the control for time since first human settlement in that table is replaced with the measure for the migration distance from East Africa compiled by Ashraf and Galor(2013). State Age is based on the emergence of either a proto-state or a full state and was assembled by Borcan, Olsson, and Putterman (2018) and it represents the time elapsed since state emergence as of $2000 \mathrm{CE}$ (in millennia). Plants and animals represent the number of domesticable plants and animals in 10000 BCE in different regions of the world (Eurasia, India and Far East, South-East Asia, Central America and Africa, North and South America, Oceania), and they were compiled by Hibbs and Olsson (2004). Agyears (time since the transition of agriculture as of 2000 CE) was assembled by Putterman with Trainor (2006 [revised 2018]). Distances to pristine state are calculated as the length of the shortest curve between the centroid of each country and the centroid of its assigned pristine state (the region from which state diffusion into the territory of the country in question is most likely to have originated). The geographic and climatic controls and historical variables' construction is detailed in the Additional data subsection of this Appendix. Robust standard errors in parentheses. ${ }^{* * *} \mathrm{p}<0.01,{ }^{* *}$ $\mathrm{p}<0.05,{ }^{*} \mathrm{p}<0.1$ 
Table A12: State Age and the Transition to Agriculture in Non-Pristine States - IV first stage estimates using distance from East Africa in place of time since first human settlement (robustness test)

\begin{tabular}{lccc}
\hline \hline & \multicolumn{3}{c}{ Time since agriculture (ky) } \\
\hline & $(1)$ & $(2)$ & $(3)$ \\
Plants & 0.010 & $0.024^{*}$ & 0.025 \\
& $(0.014)$ & $(0.014)$ & $(0.048)$ \\
Animals & $0.323^{* * *}$ & $0.228^{* * *}$ & 0.106 \\
& $(0.046)$ & $(0.058)$ & $(0.173)$ \\
Geography & $0.468^{*}$ & $0.474^{*}$ & $0.990^{* * *}$ \\
& $(0.245)$ & $(0.249)$ & $(0.266)$ \\
Distance to pristine state & & $-0.163^{* * *}$ & $-0.589^{* * *}$ \\
& & $(0.042)$ & $(0.153)$ \\
Migratory distance from East Africa & & $0.030^{* *}$ & $0.230^{* * *}$ \\
& & $(0.014)$ & $(0.054)$ \\
Observations & \multicolumn{3}{c}{} \\
R-squared & 151 & 150 & 123 \\
Controls & 0.671 & 0.700 & 0.810 \\
Diffusion Region & No & No & Yes \\
& No & No & Yes \\
\hline
\end{tabular}

The table presents OLS regression estimates of the first stage in the IV regressions reported in Table A10 in the paper (time since transition to agriculture as the dependent variables, and the instruments as the main independent variables). We control for migratory distance from East Africa (Ashraf and Galor, 2013) instead of time since first human settlement. State Age was assembled by Borcan, Olsson, and Putterman (2018) and it represents the time elapsed since state emergence as of $2000 \mathrm{CE}$ (in millennia). Agyears (time since the transition to agriculture as of $2000 \mathrm{CE}$ ) was assembled by Putterman with Trainor (2006 [revised 2018]). Distances to pristine state are calculated as the length of the shortest curve between the centroid of each country and the centroid of its assigned pristine state (the region from which state diffusion into the territory of the country in question is most likely to have originated). The geographic and climatic controls and historical variables' construction is detailed in the Additional data subsection of this Appendix. Robust standard errors in parentheses. ${ }^{* * *} \mathrm{p}<0.01,{ }^{* *} \mathrm{p}<0.05,{ }^{*} \mathrm{p}<0.1$ 
Table A13: State Age and the Transition to Agriculture in Non-Pristine States - OLS estimates using distance from East Africa in place of time since first human settlement (robustness test)

\begin{tabular}{lccc}
\hline \hline & \multicolumn{3}{c}{ State Age } \\
\hline & $(1)$ & $(2)$ & $(3)$ \\
Time since agriculture (ky) & $0.430^{* * *}$ & $0.361^{* * *}$ & $0.312^{* * *}$ \\
& $(0.025)$ & $(0.029)$ & $(0.057)$ \\
Distance to pristine state & & $-0.090^{* * *}$ & $-0.200^{*}$ \\
& & $(0.024)$ & $(0.108)$ \\
Migratory distance from East Africa & & -0.001 & 0.054 \\
& & $(0.011)$ & $(0.042)$ \\
Observations & & & \\
R-squared & 151 & 150 & 123 \\
Controls & 0.609 & 0.654 & 0.827 \\
Diffusion Region & No & No & Yes \\
& No & No & Yes \\
\hline
\end{tabular}

The table presents OLS regression estimates of the relationship between time since the emergence of states as of $2000 \mathrm{CE}$ and time since transition to agriculture. We control for migratory distance from East Africa (Ashraf and Galor, 2013) instead of time since first human settlement. State Age was assembled by Borcan, Olsson, and Putterman (2018) and it represents the time elapsed since state emergence as of $2000 \mathrm{CE}$ (in millennia). Agyears (time since the transition to agriculture as of $2000 \mathrm{CE}$ ) was assembled by Putterman with Trainor (2006 [revised 2018]). Distances to pristine state are calculated as the length of the shortest curve between the centroid of each country and the centroid of its assigned pristine state (the region from which state diffusion into the territory of the country in question is most likely to have originated). The geographic and climatic controls and historical variables' construction is detailed in the Additional data subsection of this Appendix. Robust standard errors in parentheses. ${ }^{* * *} \mathrm{p}<0.01,{ }^{* *} \mathrm{p}<0.05,{ }^{*} \mathrm{p}<0.1$ 
Table A14: State Age and the Transition to Agriculture in Pristine States - Robustness with the original version of time since first human settlement data.

\begin{tabular}{lcccc}
\hline \hline & \multicolumn{4}{c}{ State Age } \\
\hline & $(1)$ & $(2)$ & $(3)$ & $(4)$ \\
Time since agriculture (ky) & & & & \\
& $0.414^{* * *}$ & $0.669^{* *}$ & $0.591^{* *}$ & $0.587^{* *}$ \\
Time since first human settlement - original version $(\mathrm{ky})$ & $(0.061)$ & $(0.161)$ & $(0.177)$ & $(0.060)$ \\
& & -0.022 & & \\
& & $(0.020)$ & & \\
Observations & & & & \\
R-squared & 8 & 8 & 8 & 8 \\
Controls & 0.729 & 0.790 & 0.925 & 0.979 \\
\hline
\end{tabular}

The table presents OLS regression estimates of the relationship between time since full state emergence as of $2000 \mathrm{CE}$ and time since the agriculture transition in 8 countries identified as places of emergence of pristine states. It parallels Table 1 of the paper, but substitutes the original version of the time since first human settlement data of Ahlerup and Olsson (2012) for the updated version used elsewhere. In column 1 we present the unconditional estimate, in columns 2-4 we control for historical and geographical characteristics (column 2: country centroid absolute latitude, column 3: we add distance to coast and rivers and average elevation, column 4: we add precipitation, average temperature and percentage of people at risk of malaria to the controls of column 2 , leaving out the controls added in column 3). The time since state emergence is calculated and coded in Borcan, Olsson, and Putterman (2018). The time since the transition to agriculture is compiled by Putterman with Trainor (2006 [revised 2018]). The geographic and climatic controls and historical variables' construction is detailed in the Additional data subsection of this Appendix. Robust standard errors in parentheses. ${ }^{* * *} \mathrm{p}<0.01,{ }^{* *} \mathrm{p}<0.05,{ }^{*} \mathrm{p}<0.1$ 
Table A15: State Age and the Transition to Agriculture in Non-Pristine States - IV estimates; Robustness with the original version of time since first human settlement.

\begin{tabular}{lccc}
\hline \hline & \multicolumn{3}{c}{ State Age } \\
\hline & $(1)$ & $(2)$ & $(3)$ \\
& & & \\
Time since agriculture (ky) & $0.410^{* * *}$ & $0.314^{* * *}$ & $0.409^{* * *}$ \\
& $(0.034)$ & $(0.049)$ & $(0.078)$ \\
Distance to pristine state & & $-0.107^{* * *}$ & -0.064 \\
& & $(0.028)$ & $(0.057)$ \\
Time since first human settlement - original version $(\mathrm{ky})$ & -0.000 & -0.001 \\
& & $(0.001)$ & $(0.002)$ \\
& & & \\
Observations & 151 & 150 & 123 \\
R-squared & 0.607 & 0.638 & 0.819 \\
Controls & No & No & Yes \\
Diffusion Region & No & No & Yes \\
First stage F-statistic & 103.44 & 61.67 & 20.94 \\
Wooldridge's test statistic & $1.87 \mid .39$ & $2.93 \mid .23$ & $1.28 \mid .53$ \\
\hline
\end{tabular}

The table presents two-stage least squares regression estimates of the relationship between the time since state emergence and the time since transition to agriculture, in 151 countries, excluding 8 countries identified as places of emergence of pristine states. It parallels Table 2 in the paper, but substitutes the original version of the time since first human settlement data of Ahlerup and Olsson (2012) for the updated version used elsewhere. State Age is based on the emergence of either a proto-state or a full state and was assembled by Borcan, Olsson, and Putterman (2018) and it represents the time elapsed since state emergence as of $2000 \mathrm{CE}$ (in millennia). Plants and animals represent the number of domesticable plants and animals in 10000 BCE in different regions of the world (Eurasia, India and Far East, South-East Asia, Central America and Africa, North and South America, Oceania), and they were compiled by Hibbs and Olsson (2004). Agyears (time since the transition of agriculture as of $2000 \mathrm{CE}$ ) was assembled by Putterman with Trainor (2006 [revised 2018]). Distances to pristine state are calculated as the length of the shortest curve between the centroid of each country and the centroid of its assigned pristine state (the region from which state diffusion into the territory of the country in question is most likely to have originated). The geographic and climatic controls and historical variables' construction is detailed in the Additional data subsection of this Appendix. Robust standard errors in parentheses. ${ }^{* * *} \mathrm{p}<0.01,{ }^{* *} \mathrm{p}<0.05,{ }^{*} \mathrm{p}<0.1$ 


\section{References}

Ahlerup, Pelle and Ola Olsson. 2012. "The roots of ethnic diversity." Journal of Economic Growth 17 (2): 71-102.

Ashraf, Quamrul and Oded Galor. 2013. "The 'Out of Africa' hypothesis, human genetic diversity, and comparative economic development." American Economic Review 103(1): 1-46.

Borcan, Oana, Ola Olsson, and Louis Putterman. 2018. "State history and economic development: evidence from six millennia." Journal of Economic Growth 23 (1): 1-40.

Crowley, Brooke. 2010. "A refined chronology of prehistoric Madagascar and the demise of the megafauna," Quarternary Science Reviews 29 (19-20): 2591-603.

Gallup, John L. and Jeffrey D. Sachs. 2001. "The economic burden of malaria." The American Journal of Tropical Medicine and Hygiene 64(1$2)$ : 85-96.

Hammer, Michael, August Woerner, Fernando Mendez, Joseph Watkins, and Jeffrey Wall. 2011. "Genetic evidence for archaic admixture in Africa," PNAS 108 (37): 15123-8.

Hibbs, Douglas A. and Ola Olsson. 2004. "Geography, biogeography, and why some countries are rich and others are poor." Proceedings of the National Academy of Sciences 101 (10): 3715-20.

Nordhaus, William D. 2006. "Geography and macroeconomics: new data and new findings." Proceedings of the National Academy of Sciences 103(10):3510-17.

Olsson, Ola and Douglas A. Hibbs. 2005. "Biogeography and long-run economic development." European Economic Review 49 (4): 909-38.

Oppenheimer, Stephen. 2003. Out of Eden: The Peopling of the World. London: Constable and Robinson. 
Oppenheimer, Stephen. 2012a. "A single southern exit of modern humans from Africa: Before or after Toba?" Quaternary International 258: 88-99.

Oppenheimer, Stephen. 2012b. "Out-of-Africa, the peopling of continents and islands: Tracing uniparental gene trees across the map." Philosophical Transactions of The Royal Society B 367 (1590): 770-84.

Oppenheimer, Stephen. 2014. "Modern humans spread from Aden to the antipodes with passengers and when?" In Southern Asia, Australia and the Search for Human Origins, edited by Robin Dennell and Martin Porr, 228-42. New York: Cambridge University Press.

Putterman, Louis and Cary A. Trainor. 2006 [revised 2018]. "Agricultural transition year - country data set." Brown University Department of Economics. http://www.brown.edu/Departments/Economics/ Faculty/Louis_Putterman/agricultural\%20data\%20page.htm.

Putterman, Louis. 2008. "Agriculture, Diffusion, and Development: Ripple Effects of the Neolithic Revolution." Economica 75: 729-48.

Ranaweera, Lanka, Supannee Kaewsutthi, Aung Tun, Hathaichanoke Boonyarit, Samerchai Poolsuwan, and Patcharee Lertrit. 2014. "Mitochondrial DNA history of Sri Lankan ethnic people: their relations within the island and with the Indian subcontinental populations," Journal of Human Genetics 59: 28-36.

Soares, Pedro, Farida Alshamali, Joana Pereira, Veronica Fernandes, Nuno Silva, Carla Afonso, Marta Costa, Eliska Musilova, Vincent Macaulay, Martin Richards, Viktor Cerny, and Luosa Pereira. 2012. "The expansion of mtDNA haplogroup L3 within and out of Africa," Molecular Biology and Evolution 29 (3): 915-27. 